Illinois State University

ISU ReD: Research and eData

Theses and Dissertations

$10-4-2016$

\title{
Membrane biophysics of Listeria monocytogenes: analysis of an alternate pathway of branched-chain fatty acid biosynthesis and elasticity of fatty acid utilization
}

Laura E. Kuczek

Illinois State University, lekuczek@gmail.com

Follow this and additional works at: https://ir.library.illinoisstate.edu/etd

Part of the Biology Commons, Microbiology Commons, and the Molecular Biology Commons

\section{Recommended Citation}

Kuczek, Laura E., "Membrane biophysics of Listeria monocytogenes: analysis of an alternate pathway of branched-chain fatty acid biosynthesis and elasticity of fatty acid utilization" (2016). Theses and Dissertations. 621.

https://ir.library.illinoisstate.edu/etd/621

This Thesis is brought to you for free and open access by ISU ReD: Research and eData. It has been accepted for inclusion in Theses and Dissertations by an authorized administrator of ISU ReD: Research and eData. For more information, please contact ISUReD@ilstu.edu. 
MEMBRANE BIOPHYSICS OF LISTERIA MONOCYTOGENES: ANALYSIS OF AN ALTERNATE PATHWAY OF BRANCHED-CHAIN FATTY ACID BIOSYNTHESIS AND ELASTICITY OF FATTY ACID UTILIZATION

\author{
Laura E. Kuczek
}

45 Pages

The membrane homeostasis of the psychrotolerant foodborne pathogen Listeria monocytogenes involves maintaining fluidity in a range of different conditions by incorporation of specific branched-chain fatty acids (BCFAs). BCFAs are synthesized through a well-characterized pathway from branched-chain amino acids into short branched-chain acyl-CoAs followed by elongation by the FAS II system. Branched-chain alpha-keto acid dehydrogenase (Bkd) is a major player in this pathway. MOR401 is a transposon insertion mutant deficient in Bkd and has decreased membrane BFCAs. Low levels of BCFAs in L. monocytogenes are linked to diminished growth, less resistance to antimicrobials, and a severe reduction in virulence. Rescued growth and survivability of MOR401 can be achieved by media supplementation with BCFA precursors. Feeding the mutant various branched-chain carboxylic acids induced the production of BCFAs and restored growth. After culturing in the presence of novel BCFA C6 precursors 2ethylbutyrate and 2-methylpentanoate, MOR401 possessed restored survivability after one hour of incubation with protamine, a cationic antimicrobial peptide. 
Production of BCFAs in MOR401 suggests the existence of a bypass pathway of BCFA biosynthesis. Exogenous fatty acid precursors are proposed to be utilized by the activity of the enzymes Ptb and Buk, products of genes located just upstream of the $b k d$ gene cluster, which work to prime exogenous short chain carboxylic acids for BCFA biosynthesis. To further study the role of the proposed pathway, a buk knockout mutant was constructed and grown in BHI medium supplemented with natural and unnatural BCFA precursors to verify its ability to utilize these substrates in Buk's absence. Lack of novel fatty acid incorporation confirms the bypass pathway enzymes' importance in the conversion of carboxylic acids into activated of acyl CoAs for elongation and addition into the membrane.

BCFAs dominate the membrane of L. monocytogenes, which is unlike other organisms which utilize unsaturated fatty acids to maintain membrane fluidity. How then does $L$. monocytogenes modulate its membrane fluidity during infection of a host? Serum fatty acids are straight chain fatty acids and straight chain unsaturated fatty acids. To investigate L. monocytogenes' likely in vivo membrane fatty acid composition and growth, wild type strain and MOR401 were cultured in fetal bovine serum. Following the ex vivo growth studies, fatty acid analysis of the cell membranes was carried out. The results show that even though $L$. monocytogenes does not possess the machinery needed to synthesize SCUFAs, it is indeed able to utilize and benefit from SCUFA incorporation into the membrane.

KEYWORDS: Branched-chain fatty acids, Listeria monocytogenes, Membrane fluidity, Butyrate kinase 
MEMBRANE BIOPHYSICS OF LISTERIA MONOCYTOGENES: ANALYSIS OF AN ALTERNATE PATHWAY OF BRANCHED-CHAIN FATTY ACID BIOSYNTHESIS AND ELASTICITY OF FATTY ACID UTILIZATION

\author{
LAURA E. KUCZEK
}

A Thesis Submitted in Partial Fulfillment of the Requirements for the Degree of

\title{
MASTER OF SCIENCE
}

School of Biological Sciences

ILLINOIS STATE UNIVERSITY 
(C) 2016 Laura E. Kuczek 
MEMBRANE BIOPHYSICS OF LISTERIA MONOCYTOGENES: ANALYSIS OF AN ALTERNATE PATHWAY OF BRANCHED-CHAIN FATTY ACID BIOSYNTHESIS AND ELASTICITY OF FATTY ACID UTILIZATION

LAURA E. KUCZEK

COMMITTEE MEMBERS:

Brian J. Wilkinson, Co-Chair

Craig Gatto, Co-Chair

Tom Hammond 


\section{ACKNOWLEDGMENTS}

First and foremost, I would like to express my deepest gratitude to Dr. Brian J. Wilkinson for steady guidance throughout the duration of my graduate career at Illinois State University. His extensive knowledge, experience, and direction provided me with a robust framework with which to carry out this thesis. In addition, I wish to thank to my committee members Dr. Craig Gatto and Dr. Tom Hammond who have aided this project by their beneficial suggestions and advice. I owe many thanks to Dr. R. K. Jayaswal for his belief in my capabilities and for allowing me the opportunity to gain valuable undergraduate lab experience. I also extend my gratitude to all the faculty of the School of Biological Sciences whose instruction has helped me far beyond the classroom.

I deeply thank all lab members and friends within the department for good times, much-needed encouragement, and willingness to assist at a moment's notice. I would also like to express my sincerest gratitude to Dr. Gatto, Dr. Juliano, and Phi Sigma for generously providing financial support to me and my fellow graduate students during our time at Illinois State University.

And I could not have gotten this far without the love of my family, Greg, Carol, and Sarah Kuczek. The values they instilled in me and their unwavering support in everything I have pursued have, without a doubt, contributed to all the best parts of my self and my accomplishments.

L. E. K. 


\section{CONTENTS}

\section{Page}

ACKNOWLEDGMENTS $\quad$ i

CONTENTS

CHAPTER I TABLES $\quad$ iv

CHAPTER II TABLES $\quad$ v

CHAPTER I FIGURES

CHAPTER II FIGURES Nii

CHAPTER III FIGURES Viii

CHAPTERS

I. CHARACTERIZATION OF AN ALTERNATE

BRANCHED-CHAIN FATTY ACID BIOSYNTHESIS

PATHWAY BY KNOCKOUT OF BUTYRATE KINASE

IN LISTERIA MONOCYTOGENES

Introduction

Materials and Methods

buk Mutant Construction $\quad 8$

Growth Studies $\quad 10$

Membrane Fatty Acid Analysis $\quad 10$

Results 11

Discussion $\quad 12$

$\begin{array}{ll}\text { References } & 23\end{array}$ 
II. GROWTH OF A LISTERIA MONOCYTOGENES BKD MUTANT IN SERUM TO ANALYZE BRANCHED-CHAIN FATTY ACID PREFERENCE IN MEMBRANE INCORPORATION

Introduction $\quad 28$

Materials and Methods $\quad 30$

Growth Studies $\quad 30$

Membrane Fatty Acid Analysis $\quad 30$

Results 31

Discussion $\quad 32$

References $\quad 36$

III. THE EFFECTS OF NOVEL FATTY ACIDS DERIVED FROM SHORT BRANCHED-CHAIN C6 CARBOXYLIC ACIDS ON THE FUNCTIONAL MEMBRANE REQUIREMENTS OF A LISTERIA MONOCYTOGENES BCFA-DEFICIENT MUTANT

Introduction

Materials and Methods

40

Results

40

Discussion

41

References 


\section{CHAPTER I TABLES}

Table $\quad$ Page

1. Primers used and corresponding restriction endonuclease sites 19

2. Fatty acid analysis of wild type $10403 \mathrm{~S}, \mathrm{MOR} 401$, and the buk mutant supplemented with various BCFA precursors at $37^{\circ} \mathrm{C}$ 


\section{CHAPTER II TABLES}

Table $\quad$ Page

1. Fatty acid profile of wild type $10403 \mathrm{~S}$ and MOR401 grown in 50\% fetal bovine serum and $1 \mathrm{mM} 2$-methylbutyrate at $10^{\circ} \mathrm{C}$ 


\section{CHAPTER I FIGURES}

Figure $\quad$ Page

1.1 Gas chromatograph of MOR401 at $37^{\circ} \mathrm{C} . \quad 17$

1.2 Gas chromatograph of MOR401 supplemented with 2-MB at $37^{\circ} \mathrm{C} . \quad 17$

1.3 Gas chromatograph of MOR401 supplemented with 2-MP at $37^{\circ} \mathrm{C}$. 18

1.4 Gas chromatograph of MOR401 supplemented with 2-EB at $37^{\circ} \mathrm{C}$. 18

2. Creation of the construct transformed into a L. monocytogenes $10403 \mathrm{~S}$ background.

3. Influence of 2-methylbutyrate, 2-ethylbutyrate, and 2-methylpentanoate on the growth of wild type strain 10403S, MOR401, and the buk mutant at $37^{\circ} \mathrm{C}$. 


\section{CHAPTER II FIGURES}

Figure $\quad$ Page

1. Growth of wild type $10403 \mathrm{~S}$ and MOR401 in 50\% fetal bovine serum supplemented with 2-methylbutyrate at $10^{\circ} \mathrm{C}$. 


\section{CHAPTER III FIGURES}

Figure $\quad$ Page

1. The survival of MOR401 grown in the presence of branched-chain fatty acid precursors against protamine sulfate, polymyxin $\mathrm{B}$, and mutanolysin. 


\section{CHAPTER I}

\section{CHARACTERIZATION OF AN ALTERNATE BRANCHED-CHAIN FATTY ACID BIOSYNTHESIS PATHWAY BY KNOCKOUT OF BUTYRATE KINASE IN LISTERIA MONOCYTOGENES}

\section{Introduction}

Listeria monocytogenes is a Gram-positive, rod-shaped, ubiquitous saprophyte found in environmental habitats containing soil, ground water, and decaying vegetation (Gray et al., 2006). However, L. monocytogenes is also a foodborne pathogen responsible for listeriosis, a potentially fatal infection especially dangerous in pregnant women and immunocompromised individuals. Forms of infection include sepsis, gastroenteritis, meningitis, spontaneous miscarriage, and stillbirth. Mortality rates of listeriosis are relatively high; nearly $20 \%$ of admitted hospital cases do not survive infection. This is in contrast to common sources of foodborne illness such as nontyphoidal Salmonella spp. and Clostridium perfringens, with hospitalization rates of roughly $27 \%$ and $0.6 \%$ respectively, L. monocytogenes-infected patients are hospitalized at a much higher rate of $94 \%$ (Scallan et al., 2011).

The switch between L. monocytogenes' pathogenic and peaceful soil microbe states is mediated by positive regulatory factor A (prfA), which regulates the expression of virulence genes in response to environmental signals (Gray et al., 2006). This microbe most often gains access to the host by the ingestion of food, and following its 
consumption it passes through the stomach. Acid tolerance is an important aspect of $L$. monocytogenes in that virulence and acid tolerance are strongly associated (O'Driscoll et $a l .$, 1996). If the organism cannot handle the acidity of the stomach or survival within macrophage phagosomes, the chance of proliferation of the host is diminished. Following its journey through the stomach, it travels through the digestive tract to the small intestine where the organism can cross junctions between goblet and epithelial cells. Surface proteins InlA and InlB work to enter host cells via the zipper mechanism by targeting Ecadherin and Met expressed on human cells. Once inside the host cell, L. monocytogenes manages to escape the vacuole in which it was engulfed through the activity of listeriolysin. Actin polymerization is hacked by the microbe, allowing for movement in the cytosol as well as infection of other cells. Internalization of macrophages is advantageous for L. monocytogenes as this can lead to spreading of the infection to the whole body (Ribet et al., 2015). This also includes access to the brain or any present fetus because of the organism's ability to cross the blood-brain and placental barrier (Disson et al., 2008). Fortunately, treatment of a L. monocytogenes infection does not require intense therapies if caught early. Structural analogs of ampicillin, penicillin G, trimethoprim-sulfamethoxazole, and gentamicin are the drugs of choice, and little to no resistance to these has been detected so far (Temple and Nahata, 2000; Morvan et al., 2010).

Because L. monocytogenes is a ubiquitous, saprophytic organism, it does eventually find its way into food processing facilities where biofilms can form and become sources of food contamination. Biofilms have been known to be even more 
resistant to stress and antimicrobial methods than individual cells (Frank et al., 1990), which causes extremely unsusceptible populations of cells to persist. One such strain isolated at a poultry food plant in the United States was found to be established in the facility for at least 12 years (Tompkin et al., 2002).

These biofilms are difficult to totally eradicate due to L. monocytogenes' adaptations to growth in relatively extreme conditions. Outbreaks of $L$. monocytogenes continue to be a major problem in the food industry (http://www.cdc.gov/listeria/outbreaks). The FDA upholds a zero tolerance policy towards L. monocytogenes in food products; while beneficial in safeguarding the health of immunodeficient individuals, this rule in turn leads to revenue losses in the hundreds of millions of dollars in the event of each outbreak. For example, a 2008 outbreak from a meat processing facility in Canada that caused 57 hospital cases and 24 deaths cost approximately $\$ 242$ million Canadian dollars, which included costs to the food facility, individual case costs, and federal outbreak response costs (Thomas et al., 2015).

L. monocytogenes' ability to grow in typically unfavorable conditions such as those of refrigeration temperature, adverse $\mathrm{pH}$, and high salt content makes it a formidable foodborne pathogen (Shabala et al., 2008) because many of these are utilized in food preservation. This resilience is due in part to the organism's ability to modulate its cell membrane fluidity by the incorporation of specific fatty acids. Homeoviscous adaptation by addition of particular branched-chain fatty acids (BCFAs), a characteristic of Gram positive bacteria, is related to virulence and adaptation to outside stresses in $L$. monocytogenes (Giotis et al., 2007; Sun et al., 2012). 
Membranes lipids, although made up into a relatively simple bilayer structure, play crucial roles in the regulation of membrane-associated enzymes, active and passive transport of solutes across the permeable barrier, energy generation via ion gradients, and cell signaling pathways (Hazel et al., 1995). Without proper maintenance of membrane homeostasis during regularly encountered conditions such as changes in temperature, $\mathrm{pH}$, and osmolarity, a host of vital cell processes are at risk. Maintaining membrane integrity during times of stress involves controlling membrane fluidity by several different mechanisms. For organisms such as L. monocytogenes, fatty acid shortening and incorporation of different fatty acids types which confer desired properties into membrane lipids is how fluidity is regulated (Zhu et al., 2005a). The extent of membrane fluidity is related to the type of fatty acids and how they "pack" to differing degrees. Saturated fatty acids pack tightly producing a more rigid membrane, while unsaturated fatty acids and branched-chain fatty acids increase packing distance between membrane fatty acids producing a fluid state. The steric hindrance of the methyl branch on a BCFA causes the membrane to organize into a more fluid arrangement. The same effect can be seen in the kink created by the double bond of an unsaturated fatty acid (Poger et al., 2014). Making use of a variety of fatty acids causes different effects on membrane fluidity, which is the reason they are incorporated to varying degrees depending on external circumstances (Cronan et al., 1975).

The fatty acid profile of L. monocytogenes fluctuates with environmental conditions such as temperature and $\mathrm{pH}$, but BCFAs consistently make up greater than 90\% of membrane fatty acids whereas straight-chain fatty acids (SCFAs) are part of the 
membrane to a much lesser degree (Annous et al., 1997). BCFAs of the iso and anteiso series are common to L. monocytogenes and other closely related species (Kaneda, 1963a; Raines et al., 1968) with iso and anteiso BCFAs containing one methyl group at the penultimate and antepenultimate positions, respectively.

At $37^{\circ} \mathrm{C}$ in L. monocytogenes $10403 \mathrm{~S}$, anteiso C15:0, anteiso C17:0, and iso C15:0 fatty acids make up the majority of the membrane fatty acids at 40.7, 31.7 , and $13.0 \%$ respectively. However at $5^{\circ} \mathrm{C}$, anteiso $\mathrm{C} 15: 0$ increases in percentage to $65.7 \%$ and iso $\mathrm{C} 17: 0$ to $17.2 \%$ while anteiso $\mathrm{C} 17: 0$ is reduced to $6.2 \%$ of membrane fatty acids (Annous et al., 1997). Anteiso BCFAs possess a lower phase transition temperature than iso BCFAs because the methyl group is located further from the end of the fatty acid chain, which causes looser packing in the membrane (Lindström et al., 2006). The greatest proportion of BCFAs are anteiso C15:0, a fatty acid consisting of a 14-carbon chain with a methyl branch at the $12^{\text {th }}$ position (12-methyltetradecanoic acid). Anteiso C15:0 has been found to confer greater membrane fluidity and thus, plays a significant role in L. monocytogenes' growth at cold temperatures (Edgcomb et al., 2000).

BCFAs are synthesized from the branched-chain amino acids leucine, isoleucine, and valine. Branched-chain amino acid transaminase converts these amino acids into branched-chain $\alpha$-keto acids which are then oxidatively decarboxylated by branchedchain $\alpha$-keto acid dehydrogenase (Bkd) into short chain CoA precursors (Zhu et al., 2005b). FabH, which has greater affinity for the anteiso C15:0 and C17:0 precursor 2methylbutyryl-CoA especially at low temperatures (Singh et al., 2009), initiates the elongation process which is taken over by the FAS II pathway (Oku and Kaneda, 1988). 
The resulting BCFAs are anteiso $\mathrm{C} 15: 0$, anteiso $\mathrm{C} 17: 0$, iso $\mathrm{C} 14: 0$, iso $\mathrm{C} 16: 0$, iso $\mathrm{C} 15: 0$, and iso C17:0.

cld-1 and cld-2, two Tn917 transposon mutants deficient in BCFAs, are susceptible to low temperatures (Annous et al., 1997). The transposon insertions are located within the $b k d$ gene cluster, which consists of four open reading frames encoding the four subunits of Bkd, thus interrupting proper production of Bkd. When BCFA precursors are fed to these Bkd-deficient mutants, in particular short branched-chain carboxylic acids such as 2-methylbutyrate (2-MB), low temperature growth is restored (Annous et al., 1997; Kaneda, 1963b) and membrane fluidity is similar to that of wild type (Jones et al., 2002). These same results have also been replicated in S. aureus and $B$. subtilis mutants (Singh et al., 2008; Willecke et al., 1971). This suggests the occurrence of a bypass pathway acting to produce the CoA derivatives of the fatty acid precursors and incorporate the generated fatty acids into the cell membrane in the absence of Bkd. Bkd may not be the only enzyme involved in the generation of CoA derivatives for fatty acid biosynthesis.

Recently, it has been found that the medium supplementation of the branchedchain C6 carboxylic acid isomers 2-ethylbutyrate (2-EB) and 2-methylpentanoate (2-MP) with BCFA deficient mutant MOR401 (Sun et al., 2012) yields the production of novel fatty acids in the membrane. Gas-liquid chromatograph traces from Sen et al. (2015) display two major peaks in samples where MOR401 was supplemented with 2-EB and 2MP. These peaks correspond to the presence of novel fatty acids made through elongation of the added precursors (Figure 1.3 and 1.4) which were further analyzed by electron 
ionization mass spectroscopy. Incorporation of novel fatty acids benefitted the mutant; MOR401 shows restored growth patterns and membrane fluidity when fed $1 \mathrm{mM}$ 2-MB, 2-EB, or 2-MP (Sen et al., 2015). BCFA precursors are not confined to the usual substrates, but in fact, L. monocytogenes is able to utilize many more which in turn leads to the creation of unnatural BCFAs.

Just upstream of the $b k d$ gene cluster are $p t b$ and $b u k$, whose gene products are phosphotransbutyrylase (Ptb) and butyrate kinase (Buk) (Zhu et al., 2005b). ptb and buk were identified in L. monoctyogenes by sequence similarity to genes within the $b k d$ operon of B. subtilis and E. faecalis (Debarbouille et al., 1999; Ward et al., 1999). Although their genes are located in an operon also encoding Bkd, an important part of BCFA generation, Ptb and Buk are known to be involved in the synthesis of butyrate. Most commonly, butyrate production begins with acetyl-CoA and after a series of reactions, butyryl-CoA is converted to butyryl-phosphate by Ptb (Vital et al., 2014). Buk is then responsible for catalyzing the reversible butyryl-phosphate to butyrate reaction (Hartmanis and Gatenbeck, 1984; Hartmanis, 1987; Twarog and Wolfe, 1962). Because of their proximity to the $b k d$ gene cluster and their reversible enzymatic activity, it has been proposed that both Ptb and Buk are able to reverse their physiological directions and act upon exogenous carboxylic acids to yield the corresponding acyl CoA derivatives.

Very recently, a paper on the characterization of Ptb was published from our laboratory in which Ptb is described to possess broad substrate specificity, chain length specificity, and a preference for branched-chain substrates (Sirobhushanam et al., 2016). 
Additionally, results of an analysis of Ptb's activity with unnatural substrates such as 2EB suggest that $\mathrm{Ptb}$ is an important factor in the proposed bypass pathway.

In a manuscript submitted for publication, the second enzyme in the putative alternate pathway of BCFA biosynthesis, Buk, was characterized. Buk also displays broad substrate specificity and a preference for a specific chain length (C3-C5). Notably, Buk demonstrates a strong inclination towards activity with branched chain carboxylic acids at low temperatures and is able to utilize unnatural BCFA precursors just like Ptb.

These findings lead us to consider Ptb and Buk as the main participants in the conversion of exogenous short chain carboxylic acids to short chain acyl CoAs, which can then be elongated into membrane BCFAs by the FAS II system. To further confirm the involvement of this potential bypass pathway in priming available BCFA precursors for membrane incorporation, a buk knockout mutant was created in L. monocytogenes 10403S and analyzed for utilization of BCFA substrates. The lack of incorporation of BCFA precursors observed in this study demonstrates the importance of Buk's role in utilizing BCFA precursors for membrane incorporation.

\section{Materials and Methods}

\section{buk Mutant Construction}

Figure 2 outlines the creation of the cassette inserted into L. monocytogenes 10403S. To start, $1.25 \mathrm{~kb}$ regions directly upstream and downstream of buk (lmo1370) were amplified with Phusion DNA polymerase (Thermo Scientific). Primers used are described in Table 1. In the downstream section targeted for PCR, a small portion of buk 
was included for the purpose of retaining a ribosome binding site, which helps to reduce polar effects of the knockout. Following purification (GeneJET PCR Purification Kit, Fermentas), the fragments were digested with BamHI and ligated together so that the downstream 1250 base pairs immediately follow the 1250 base pairs of the upstream portion (Rapid DNA Ligation Kit, Thermo Scientific). This was run on a $1 \%$ agarose gel and the correct band was excised and purified (Zymoclean Gel DNA Recovery Kit, Zymo Research). This construct was ligated to cloning vector pJET1.2/blunt (CloneJET PCR Cloning Kit, Thermo Scientific) and the resulting plasmid was transformed into TOP10 competent E. coli cells. After plasmid isolation (GeneJET Plasmid Miniprep Kit, Thermo Scientific), KpnI and SalI restriction enzymes were utilized to cut the upstreamdownstream fragment from pJET. Following this, the construct was cloned into shuttle plasmid pKSV7 (Smith and Youngman, 2015) and once again transformed into TOP10 competent cells. pKSV7 isolation was carried out and digested with BamHI to match the similarly digested 802 base pair kanamycin resistance gene $k a n R$ from pCOM. The kanamycin gene was ligated into the digested pKSV7 and transformed into TOP10 competent $E$. coli cells. After confirmation of accurate construct creation, the vector was transformed by electroporation into L. monocytogenes $10403 \mathrm{~S}$ cells, which were made competent by treatment with lysozyme and penicillin G (Park and Stewart, 1990). Plasmid integration and excision was accomplished with a protocol outlined specifically for use with thermosensitive vector pKSV7 (Jordan et al., 2014). Integration of pKSV7 was ensured through serial passage of the putative knockout strain at $42^{\circ} \mathrm{C}$ in the presence of chloramphenicol and kanamycin. Plasmid excision was accomplished with repeated 
growth at $30^{\circ} \mathrm{C}$ with kanamycin and testing for successful homologous recombination was confirmed with an absence of growth of the mutant on an agar plate containing chloramphenicol. Sequencing of the mutant was performed by the University of Illinois at Urbana-Champaign Core Sequencing Facility.

\section{Growth Studies}

The growth patterns of the buk mutant with and without supplementation of $1 \mathrm{mM}$ 2-MB, 2-EB, 2-MP, and $100 \mathrm{mM}$ butyrate were compared with WT strain $10403 \mathrm{~S}$ and MOR401, a $b k d$ mutant with a Tn917 transposon insertion (O'Riordan and Sun, 2012). Bacteria were grown overnight at $37^{\circ} \mathrm{C}$ with shaking at $200 \mathrm{rpm}$ in $\mathrm{BHI}$. Overnight cultures were diluted 1:50 into fresh BHI with a flask-to-medium ration of 5:1. Cultures were incubated at $37^{\circ} \mathrm{C}$ with shaking at $200 \mathrm{rpm}$ and $\mathrm{OD}_{600}$ was monitored until stationary phase.

\section{Membrane Fatty Acid Analysis}

Cultures were grown in BHI with or without supplementation and harvested at approximately an $\mathrm{OD}_{600}$ of 0.6 (mid-log phase). The culture volume of $5 \mathrm{~mL}$ was centrifuged at $3000 \times \mathrm{g}$ for 15 minutes at $4^{\circ} \mathrm{C}$ and pellets were washed three times with cold distilled $\mathrm{H}_{2} \mathrm{O}$. Fatty acid profiles were determined by Microbial ID, Inc. (Newark, DE) where the fatty acids within the cells (wet weight 30 to $40 \mathrm{mg}$ ) were saponified, methylated, and extracted. The methyl esters were separated with an Agilent 5890 dual 
tower gas chromatograph and determined using the MIDI microbial identification system (Sherlock 4.5 microbial identification system).

\section{Results}

After sequencing, the buk mutant was grown with supplementation of various precursors to confirm its inability to utilize BCFA primers (Figure 3). The buk mutant grown with and without supplementation of BCFA precursors displayed a long lag phase similar to that of MOR401. Decreased growth of the mutant in comparison to wild type could be due to the impact of butyrate kinase's activity in other aspects of cell metabolism or stress brought on by the insertion of the kanamycin resistance gene. As expected, growth of MOR401 was restored in the presence of 2-MB (Sen et al., 2015). The buk mutant reached a greater cell density than MOR401 by stationary phase, but was still below that of 2-MB-supplemented MOR401. Addition of 2-MB, 2-EB, and 2-MP to the media did not improve growth of the buk mutant, as is the case with MOR401, validating the postulation that Buk is necessary in priming precursors for incorporation into the membrane.

Fatty acid analysis was performed on supplemented cultures by Microbial ID Inc. to assess the buk mutant's membrane fatty acid composition. As suggested by the growth curves of the buk mutant with the BCFA precursors, fatty acid composition was comparable with and without addition of primers (Table 2). Interestingly, 2-EB supplementation produced a detectable quantity of novel fatty acid, 12-ethyltetradecanoic acid, at $3.75 \%$. This unnatural fatty acid was identified through its 2.73 -minute retention 
time; Sen et al. (2015) reported presence of 12-ethyltetradecanoic acid by the addition of 2-EB in MOR401 with a retention time of 2.75 minutes (Figure 1.4). Wild type 10403S supplementation with $1 \mathrm{mM} 2$-EB yields approximately $7 \%$ of 12 -ethyltetradecanoic acid while the buk mutant yields just half of that value. The fatty acid composition of wild type grown with 2-MP shows the incorporation of 12-methylpentadecanoic acid while, in the buk mutant, none was detected. Overall, the observed results suggest that Buk is a factor in BCFA biosynthesis from exogenous short chain carboxylic acids, but redundant systems may also be involved as indicated by the incorporation of 2-EB.

\section{Discussion}

The pathways involved in maintenance of membrane fluidity by alteration of membrane fatty acid composition have been implicated in virulence (Sun et al., 2012), changes in membrane enzyme function, sensing for signal pathways involved in stress and gene expression, transport, and membrane permeability (Beney et al., 2001). In strain MOR401, resistance to stress and virulence were severely diminished (Sun et al., 2012). But in the event of BCFA precursors becoming available to the organism, regulation of virulence and stress pathways were once again restored. This study sought to confirm the involvement of one of the two suggested proteins, Buk, in priming exogenous BCFA precursors for elongation in L. monocytogenes by knocking out the buk gene.

Growth and fatty acid analysis of the mutant showed little effect of BCFA precursor supplementation. This leads us to believe that Buk is a critical role in the conversion of branched-chain carboxylic acids into BCFA precursors. Somewhat 
expectedly, a small amount of 2-EB managed to become incorporated in Buk's absence. It has been speculated that production of 12-ethyltetradecanoic acid may be a product of redundant systems in L. monocytogenes. One possibility is the existence of a second butyrate kinase. The genome of C. acetobutylicum strain ATCC 8244, another Grampositive bacillus, contains two butyrate kinase coding sequences (CA_C1660 and CA_C3075). The small percentage of novel fatty acid may be due to a previously unknown second low-activity butyrate kinase in L. monocytogenes $10403 \mathrm{~S}$.

Another proposal is that incorporation of 2-EB in the buk mutant could have occurred via closely-related enzymes not previously associated with BCFA biosynthesis such as acetate kinase, or possibly a CoA transferase or CoA ligase, which have not been characterized yet in L. monocytogenes (Horswill and Escalante-Semerena, 1999; Kumari et al., 1995).

Acetate kinase is an enzyme which takes part in excretion of acetate and ATP generation during anaerobic conditions via the phosphotransacetylase-acetate kinase pathway. Specifically, it catalyzes the reversible acetyl phosphate from acetate and ATP reaction (Wolfe, 2005). The Pta-AckA pathway has also been found to be involved with the DegU orphan response regulator, which directs motility, chemotaxis, biofilm formation, and ultimately virulence in L. monocytogenes (Gueriri et al., 2008). The activity of acetate kinase is very similar to butyrate kinase. They perform the same reactions except acetate kinase is active with specific preference for acetate. Acetate and butyrate are very similar structurally due to butyrate possessing a carbon chain with two more carbon atoms than acetate. It is reasonable to suggest that acetate kinase could be 
acting in place of Buk in the buk mutant and may be the reason for incorporation of small amounts of novel fatty acid precursor 2-EB.

Other possibilities include a CoA transferase or CoA ligase acting in place of the nonfunctional bypass pathway. L. monocytogenes encodes for several additional enzymes which perform similar functions as the proposed candidates of the bypass pathway of BCFA synthesis: propionate CoA-transferase (lmo2172), CoA-transferase (lmo2755), acetyl transferase (lmo0664), as well as fatty acid-CoA ligase (lmo0354) and acetateCoA ligase (lmo2720). Substrates of these enzymes such as acetate, butyrate, and propionate can easily fit within the active sites of the listed enzymes. Use of bulkier C5 and C6 fatty acid precursors in our studies allowed us to target Ptb and Buk, which possess more flexible active sites and therefore are able to utilize a broad range of substrates (Sirobhushanam et al., 2016; unpublished data). This is likely why there was a decreased amount of supplement incorporation; one or several of the aforementioned enzymes with more rigid active sites did not have the ability to fully utilize the supplemented BCFA precursors. We suggest that Buk and Ptb are the most probable candidates in the conversion of carboxylic acids into acyl CoA primers for BCFA synthesis.

It was thought that because of the likely occurrence of redundant systems in this organism, this study may have been best carried out by constructing a ptb knockout mutant considering the common phosphotransferase activity of Buk. However, after discovering many enzymes that perform very similar functions such as Pta reversibly 
converting acetyl-CoA and inorganic phosphate into acetyl phosphate and CoA (Wolfe, 2005), a ptb mutant would have likely yielded similar results.

Redundant systems are very common in bacteria as well as higher organisms. A consequence of gene duplication events or horizontal gene transfer, redundant genes and their products are often brought about by selective pressures which induce stress (Gevers et al., 2004). When conditions again reach a normal state, duplicates can be lost except in the instance when one gene product performs their function more effectively than the other (Kochiwa et al., 2007). A comprehensive study on B. subtilis was performed to determine essential and nonessential genes by singly inactivating each of the 4,100 genes. Only 271 were found to be required for growth, which is just under $7 \%$ of the genome (Kobayashi et al., 2003). The vast majority of genes are perhaps just advantageous but not required for the survival of the organism, or have backup systems. buk was found to be nonessential in $B$. subtilis. Given the results of the present study where the knockout of buk yielded only slightly diminished growth and a normal membrane fatty acid profile, we also observed that Buk is nonessential in L. monocytogenes. Buk is active in butyrate production and is advantageous in the utilization of exogenous fatty acid precursors, but is not required. As is evident from the incorporation of 2-EB, there are probably several alternative enzymes which can act in place of our proposed bypass pathway.

Buk, as a factor in priming carboxylic acids for fatty acid biosynthesis, is also hypothesized to play a role in signal transduction when the organism encounters fatty acids in the gut during infection. Acetate, propionate, and butyrate are the three most common human intestinal fatty acids produced from bacterial fermentation of 
carbohydrates (Scheppach, 1994). Buk displays relatively high phosphorylation activity with butyrate as well as pentanoate, isobutyrate, and isovalerate in C. acetobutylicum (Hartmanis, 1987). Also in C. acetobutylicum, high levels of phosphorylated gut carboxylic acids are associated with large changes in gene expression (Zhao et al., 2005). In light of these findings, it could be proposed that fatty acids found in the gut induce virulence factor activation in L. monocytogenes in part by the activity of Ptb and Buk. In vivo studies on the buk mutant would elucidate the bypass pathway's involvement in virulence.

Much is still not known about the implications of Ptb and Buk's roles beyond previous and present findings. For instance, prevalence of $p t b$ and $b u k$ among different microorganisms is rather lacking, even in butyrate-secreting species. If this pathway were the only source of intestinal butyrate, many gut bacteria would have these genes. Instead, most microbes tend to utilize CoA transferase in the final steps of butyrate production (Louis et al., 2004). Since L. monocytogenes possesses genes encoding Ptb, Buk, and CoA transferase, it is suggested that there is much more function to the Ptb-Buk pathway than is presently known. 


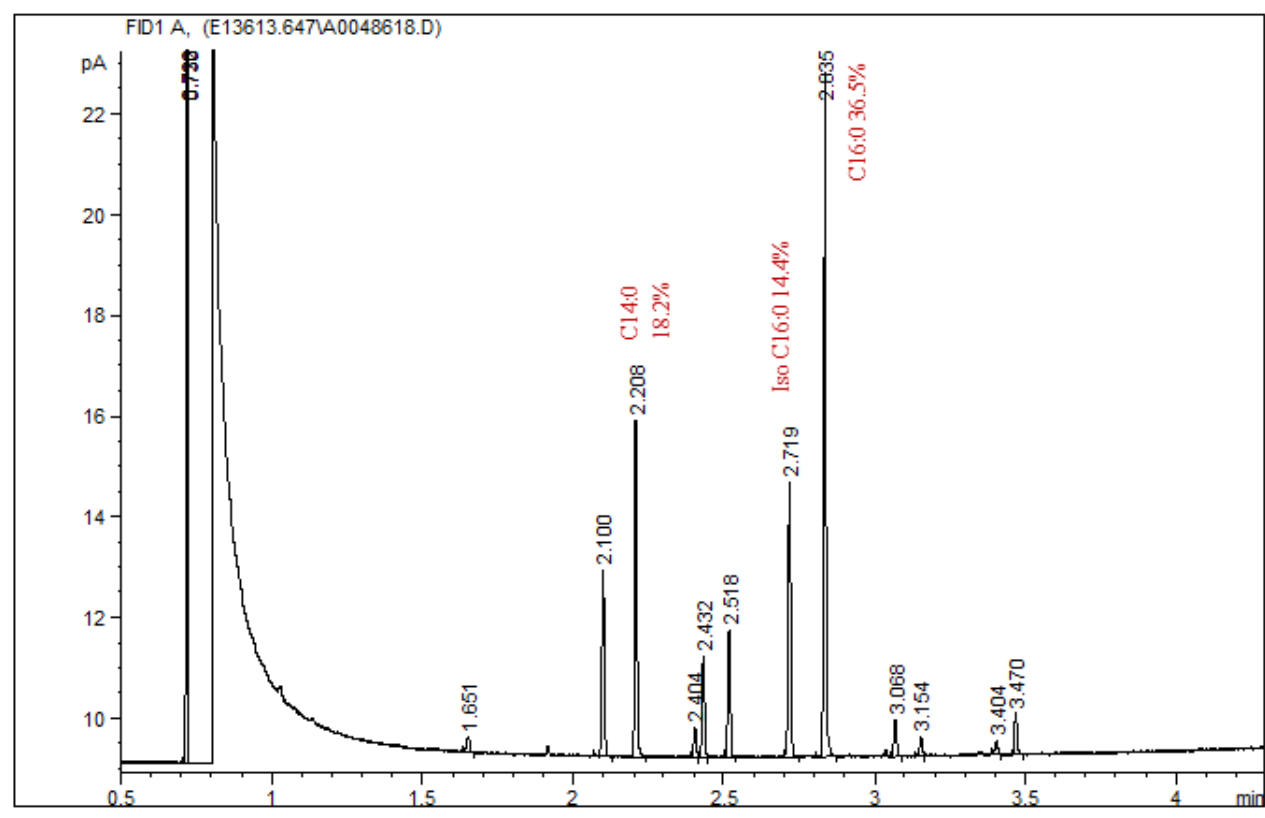

Figure 1.1 Gas chromatograph of MOR401 at $37^{\circ} \mathrm{C}$.

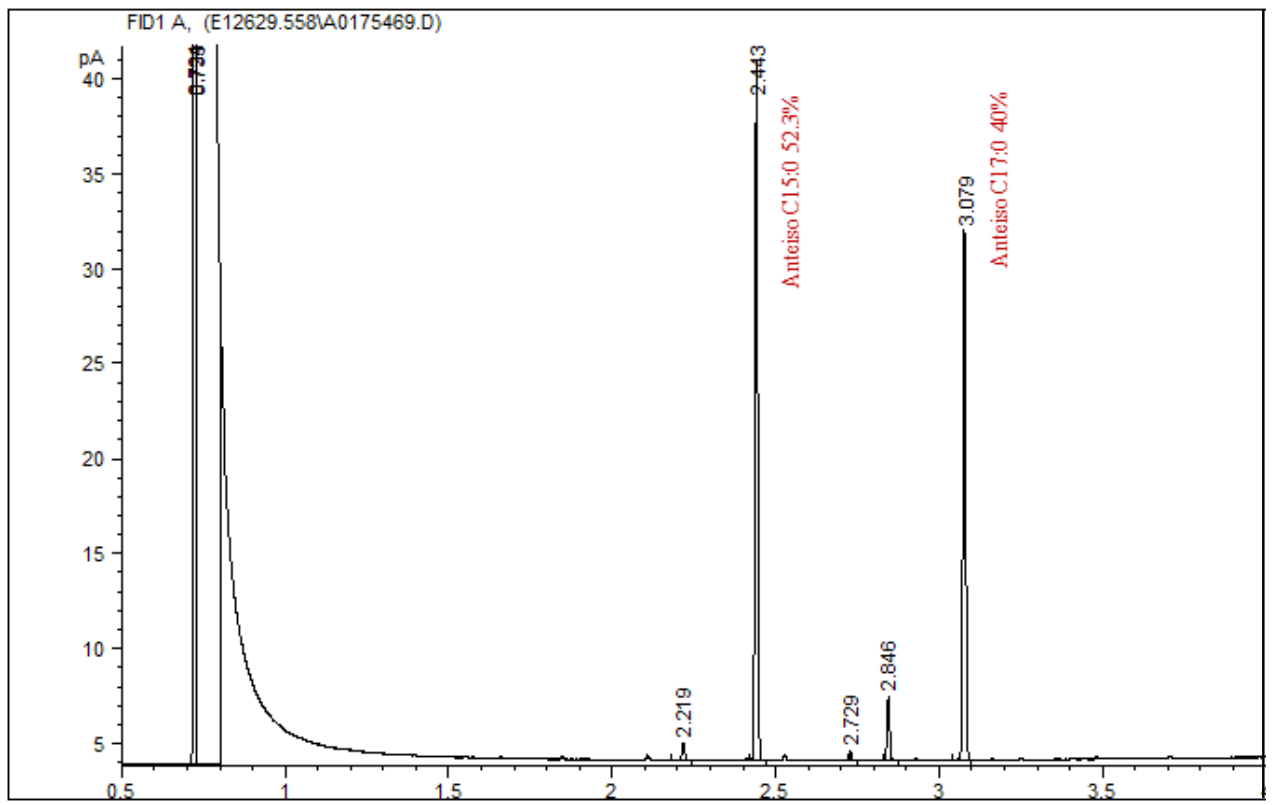

Figure 1.2 Gas chromatograph of MOR401 supplemented with 2-MB at $37^{\circ} \mathrm{C}$. 


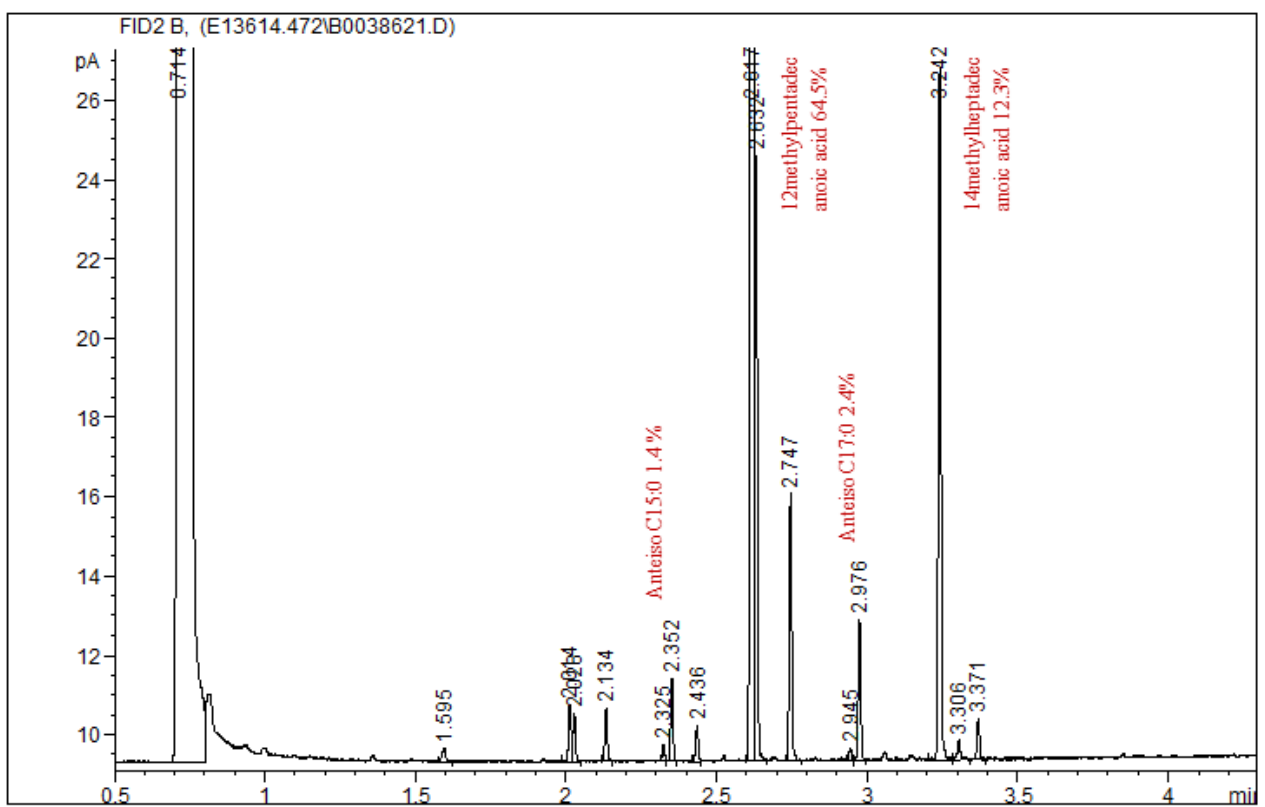

Figure 1.3 Gas chromatograph of MOR401 supplemented with 2-MP at $37^{\circ} \mathrm{C}$.

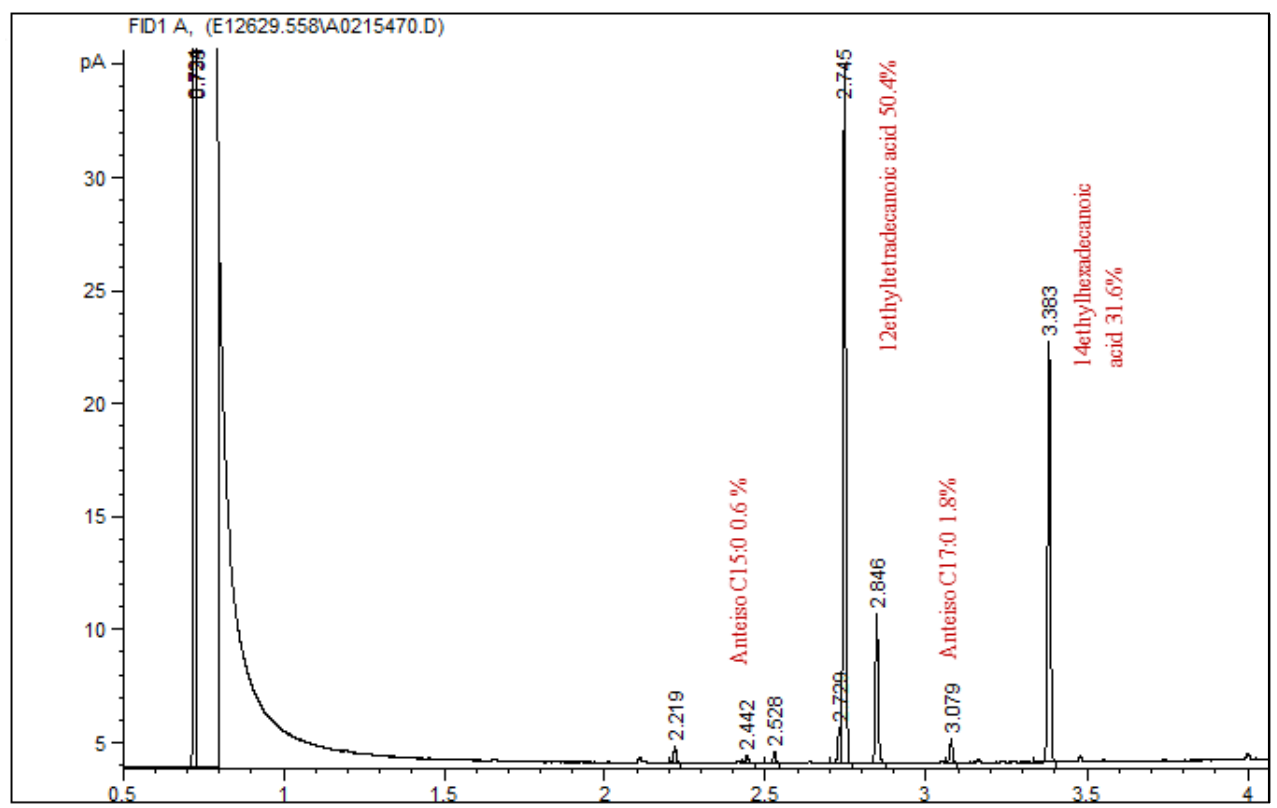

Figure 1.4 Gas chromatograph of MOR401 supplemented with 2-EB at $37^{\circ} \mathrm{C}$. 
Table 1

Primers used and corresponding restriction endonuclease sites

\begin{tabular}{|c|c|}
\hline Primers & Sequence (5' to $\left.3^{\prime}\right)$ \\
\hline $\begin{array}{l}\text { upstream } \\
\text { forward }\end{array}$ & AAAGGTACCGAGTAGAAAAAGTAGAAGAAATCAGC $(K p n I)$ \\
\hline $\begin{array}{l}\text { upstream } \\
\text { reverse }\end{array}$ & AAAGGATCCTTGCTTTCCTCCAAATTTAATTG (BamHI) \\
\hline $\begin{array}{l}\text { downstream } \\
\text { forward }\end{array}$ & AAAGGATCCTATTGAGCAAACAAACTGGA $($ BamHI) \\
\hline $\begin{array}{l}\text { downstream } \\
\text { reverse }\end{array}$ & AAAGTCGACTAATGAAGCCATCTGATTCTCC (SalI) \\
\hline
\end{tabular}




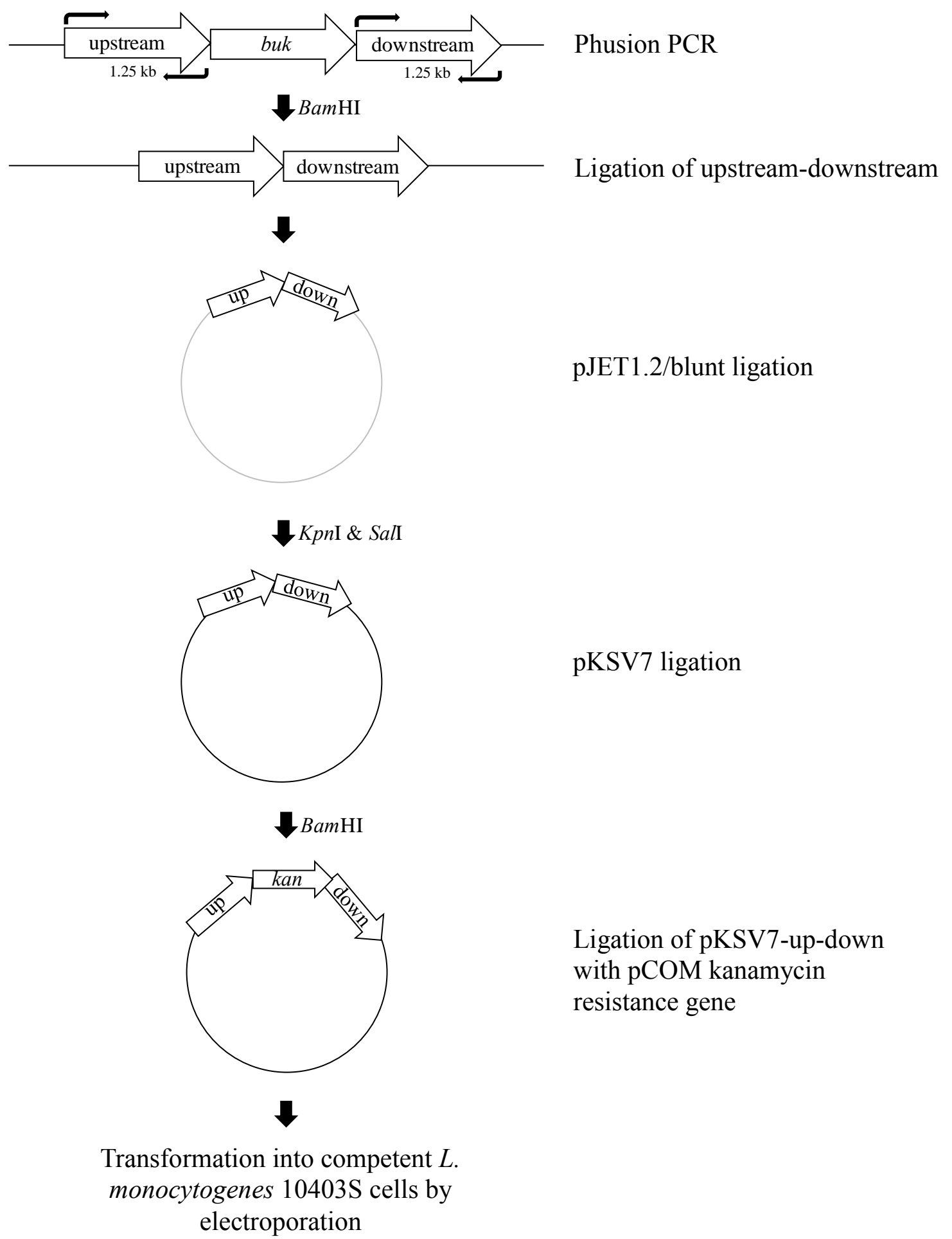

Figure 2. Creation of the construct transformed into a L. monocytogenes $10403 \mathrm{~S}$ background. 


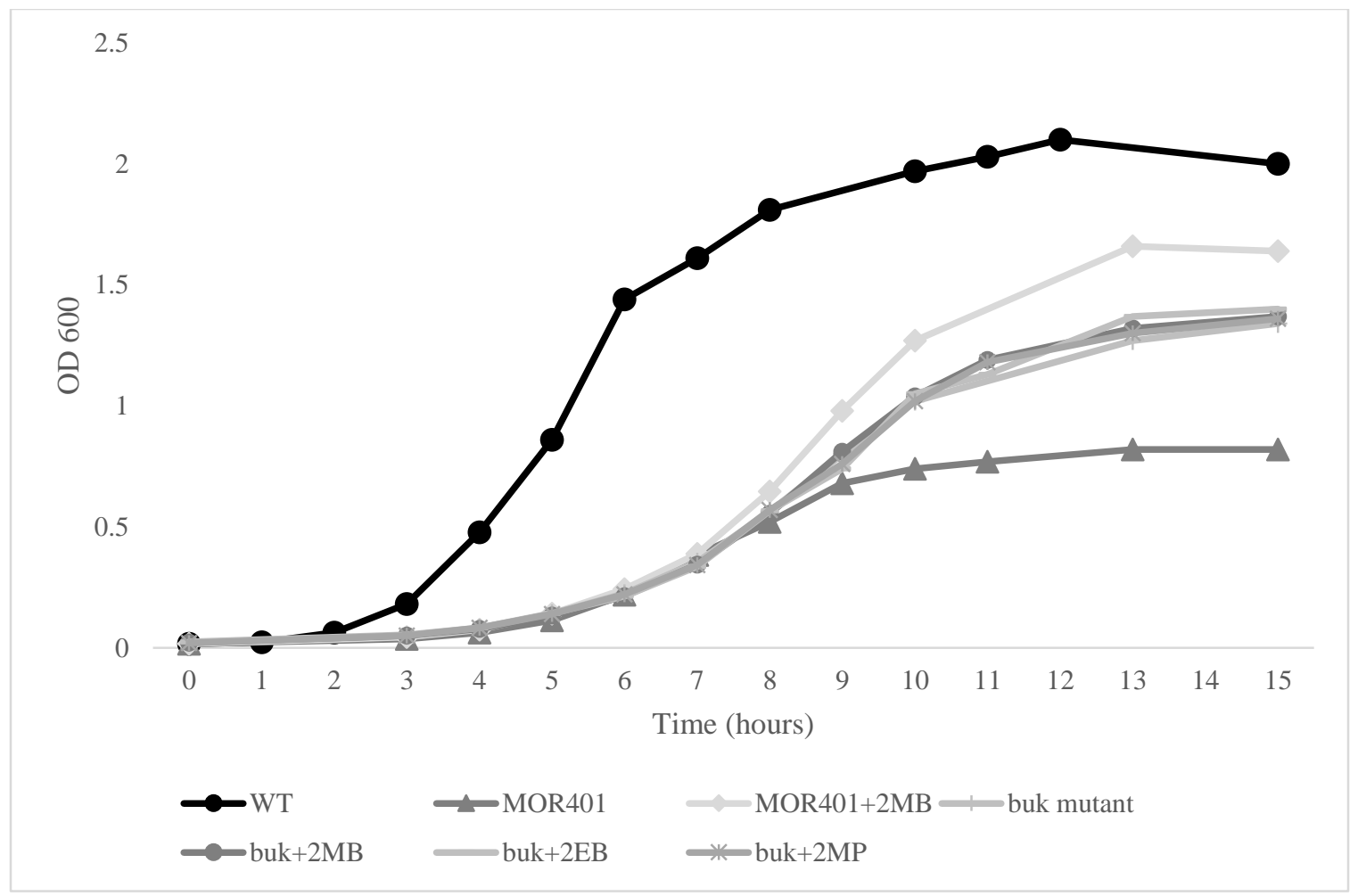

Figure 3. Influence of 2-methylbutyrate, 2-ethylbutyrate, and 2-methylpentanoate on the growth of wild type strain $10403 \mathrm{~S}, \mathrm{MOR} 401$, and the $b u k$ mutant at $37^{\circ} \mathrm{C}$. 


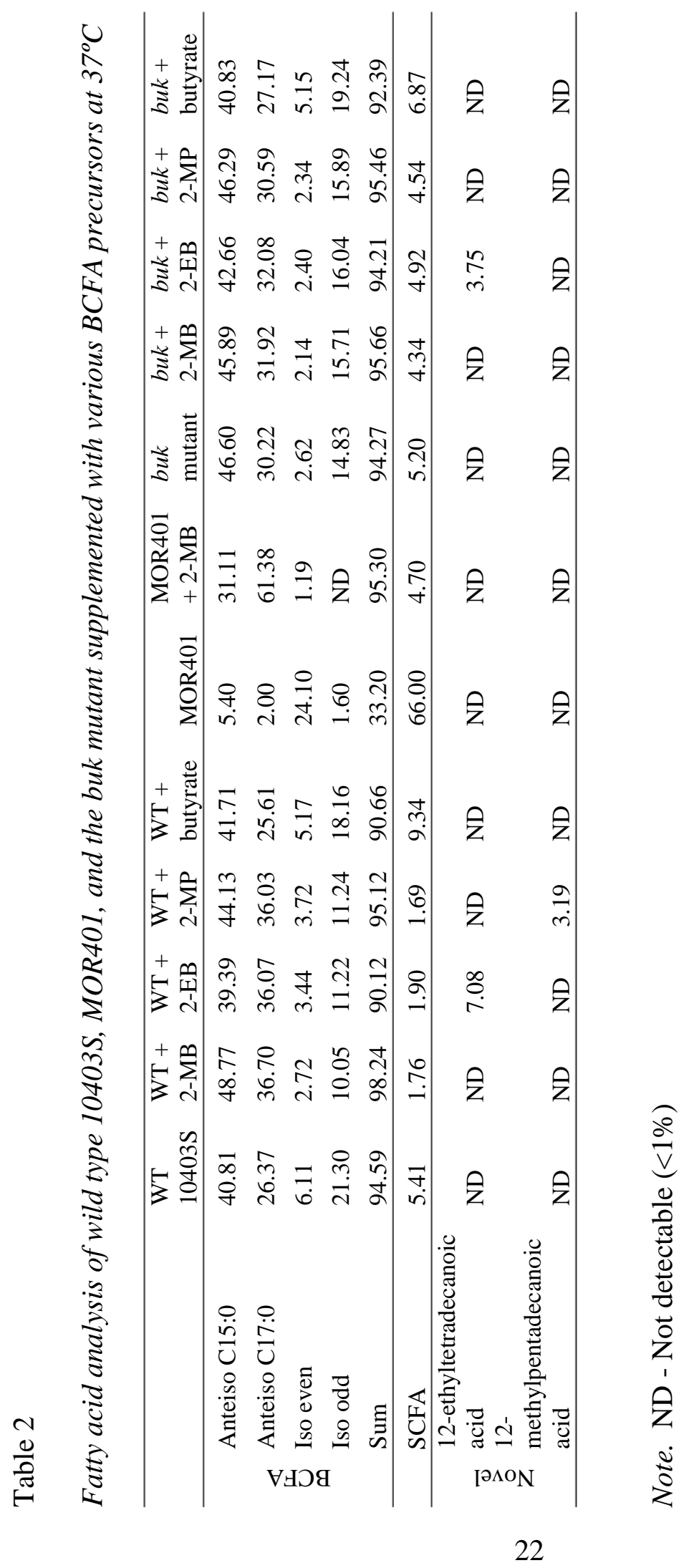




\section{REFERENCES}

Annous, B. A., Becker, L. A., Bayles, D. O., Labeda, D. P., and Wilkinson, B. J. (1997). Critical role of anteiso-C15:0 fatty acid in the growth of Listeria monocytogenes at low temperatures. Appl Environ Microbiol 63, 3887-3894.

Beney, L. and Gervais, P. (2001). Influence of the fluidity of the membrane on the response of microorganisms to environmental stresses. Appl Microbiol Biotechnol 57, 34-42.

Cronan, Jr., J. E. and Gelmann, E. P. (1975). Physical properties of membrane lipids: biological relevance and regulation. Bacteriol Rev 39, 232-256.

Debarbouille, M., Gardan, R., Arnaud, M., and Rapoport, G. (1999). Role of BkdR, a transcriptional activator of the SigL-dependent isoleucine and valine degradation pathway in Bacillus subtilis. J Bacteriol 181, 2059-2066.

Disson, O., Grayo, S., Huillet, E., Nikitas, G., Langa-Vives, F., Dussurget, O., Ragon, M., Le Monnier, A., Babinet, C., Cossart, P., and Lecuit, M. Conjugated action of two species-specific invasion proteins for fetoplacental listeriosis. Nature 455, 1114-1118.

Edgcomb, M. R., Sirimanne, S., Wilkinson, B. J., Drouin, P., and Morse, R. D. (2000). Electron paramagnetic resonance studies of the membrane fluidity of the foodborne pathogenic psychrotroph Listeria monocytogenes. Biochim Biophys Acta 1463, 31-42.

Frank, J. F. and Koffi R. A. (1990). Surface-adherent growth of Listeria monocytogenes is associated with increased resistance to surfactant sanitizers and heat. J Food Prot 53, 550-554.

Gevers, D., Vandepoele, K., Simillion, C., and Van de Peer, Y. (2004). Gene duplication and biased functional retention of paralogs in bacterial genomes. Trends Microbiol 12, 148-154.

Giotis, E. S., McDowell, D. A., Blair, I. S., and Wilkinson, B. J. (2007). Role of branched-chain fatty acids in $\mathrm{pH}$ stress tolerance in Listeria monocytogenes. Appl Environ Microbiol 73, 997-1001. 
Gray, M. J., Freitag, N. E., and Boor, K. J. (2006). How the bacterial pathogen Listeria monocytogenes mediates the switch from environmental Dr. Jekyll to pathogenic Mr. Hyde. Infect Immun 74, 2505-2512.

Gueriri, I., Bay, S., Dubrac, S., Cyncynatus, C., and Msadek, T. The Pta-Acka pathway controlling acetyl phosphate levels and the phosphorylation state of the DegU orphan response regulator both play a role in regulating Listeria monocytogenes motility and chemotaxis. Mol Microbiol 70, 1342-1357.

Hartmanis, M. G. N. (1987). Butyrate kinase from Clostridium acetobutylicum. J Biol Chem 262, 617-621.

Hartmanis, M. G. N. and Gatenbeck, S. (1984). Intermediary metabolism in Clostridium acetobutylicum: levels of enzymes involved in the formation of acetate and butyrate. Appl Environ Microbiol 47, 1277-1283.

Hazel, J. Thermal adaptation in biological membranes: is homeoviscous adaptation the explanation? Annu Rev Physiol 57, 19-42.

Horswill, A. R. and Escalante-Semerena, J. C. (1999). The prpE gene of Salmonella typhimurium LT2 encodes propionyl-CoA sythetase. Microbiology 145, 13811388.

Jones, S. L., Drouin, P., Wilkinson, B. J., and Morse, P. D. (2002). Correlation of longrange membrane order with temperature-dependent growth characteristics of parent and a cold-sensitive, branched-chain-fatty-acid-deficient mutant of Listeria monocytogenes. Arch Microbiol 177, 217-222.

Jordan, K., Fox, E. M., and Wagner, M. (2014). Listeria monocytogenes: methods and protocols. Methods Mol Biol 1157, 187-200.

Kaneda, T. (1963a). Biosynthesis of branched chain fatty acids I. isolation and identification of fatty acids from Bacillus subtilis (ACTCC 7059). J Biol Chem $23,1222-1229$.

Kaneda, T. (1963b). Biosynthesis of branched chain fatty acids II. microbial synthesis of branched long chain fatty acids from certain short chain fatty acid substrates. J Biol Chem 238, 1229-1235.

Kobayashi, K., Ehrlich, S. D., Albertini, A., Amati, G., Andersen, K. K., Arnaud, M., Asai, K., ... Ogasawara, N. (2003). Essential Bacillus subtilis genes. Proc Natl Acad Sci USA 100, 4678-4683. 
Kochiwa, H., Tomita, M., and Kanai, A. (2007). Evolution of ribonuclease H genes to avoid inheritance of redundant genes. BMC Evol Biol 7, 128.

Kumari, S., Tishel, R., Eisenbach, M., and Wolfe, A. J. (1995). Cloning, characterization, and functional expression of acs, the gene which encodes acetyl coenzyme A synthetase in Escherichia coli. Microbiology 177, 2878-2886.

Lindström, F., Thurnhofer, S., Vetter, M., and Gröbner, G. (2006). Impact on lipid membrane organization by free branched-chain fatty acids. Phys Chem Chem Phys 8, 4792-4797.

Louis, P., Duncan, S. H., McCrae, S. I., Millar, J., Jackson, M. S., and Flint, H. J. (2004). Restricted distribution of the butyrate kinase pathway among butyrate-producing bacteria from the human colon. J Bacteriol 186, 2099-2106.

Morvan, A., Moubareck, C., Leclercq, A., Hervé-Bazin, M., Bremont, S., Lecuit, M., Courvalin, P., and Le Monnier, A. (2010). Antimicrobial resistance of Listeria monocytogenes strains isolated from humans in France. Antimicrob Agents Chemother 54, 2728-2731.

O'Driscoll, B., Gahan, C. G., and Hill, C. (1996). Adaptive acid tolerance response in Listeria monocytogenes: isolation of an acid-tolerant mutant which demonstrates increased virulence. Appl Environ Microbiol 62, 1693-1698.

Oku, H. and Kaneda, T. (1988). Biosynthesis of branched-chain fatty acids in Bacillus subtilis: a decarboxylase is essential for branched-chain fatty acid synthetase. $\mathbf{J}$ Biol Chem 263, 18386-18396.

O'Riordan, M. X. D. and Sun, Y. (2012). Regulation of bacterial pathogenesis by intestinal short-chain fatty acids. Adv Appl Microbiol 29, 997-1003.

Park, S. F. and Stewart, G. S. A. B. (1990). High-efficiency transformation of Listeria monocytogenes by electroporation of penicillin-treated cells. Gene 94, 129-132.

Poger, D., Caron, B., and Mark, A. E. (2014). Effect of methyl-branched fatty acids on the structure of lipid bilayers. J Phys Chem B 118, 13838-13848.

Raines, L. J., Moss, C. W., Farshtchi, D., and Pittman, B. (1968). Fatty acids of Listeria monocytogenes. J Bacteriol 96, 2175-2177.

Ribet, D. and Cossart P. (2015). How bacterial pathogens colonize their hosts and invade deeper tissues. Microbes Infect 17, 173-183. 
Scallan, E., Hoekstra, R. M., Angulo, F. J., Tauxe, R. V., Widdowson, M. A., Roy, S. L., Jones, J. L., and Griffin, P. M. (2011). Foodborne illness acquired in the United States - major pathogens. Emerg Infect Dis 17, 7-15.

Scheppach, W. Effects of short chain fatty acids on gut morphology and function. (1994). Gut 35, S35-S38.

Sen, S., Sirobhushanam, S., Hantak, M. P., Lawrence, P., Brenna, J. T., Gatto, C., and Wilkinson, B. J. (2015). Short branched-chain C6 carboxylic acids result in increased growth, novel 'unnatural' fatty acids and increased membrane fluidity in a Listeria monocytogenes branched-chain fatty acid-deficient mutant. BBA Mol Cell Biol Lipids 1851, 1406-1415. Elsevier B.V.

Shabala, L., Lee, S. H., Cannesson, P., and Ross, T. (2008). Acid and NaCl limits to growth of Listeria monocytogenes and influence of sequence of inimical acid and $\mathrm{NaCl}$ levels on inactivation kinetics. J Food Prot 71, 1169-1177.

Singh, A. K., Zhang, Y. M., Zhu, K., Subramanian, C., Li, Z., Jayaswal, R. K., Gatto, C., Rock, C. O., and Wilkinson, B. J. (2009). FabH selectivity for anteiso branchedchain fatty acid precursors in low-temperature adaptation in Listeria monocytogenes. FEMS Microbiol Lett 301, 188-192.

Sirobhushanam, S., Galva, C., Sen, S., Wilkinson, B. J., and Gatto, C. Broad substrate specificity of phosphotransbutyrylase from Listeria monocytognenes: A potential participant in an alternate pathway for provision of acyl CoA precursors for fatty acid biosynthesis. Biochim Biophys Acta 1861, 1102-1110.

Smith, K. and Youngman, P. (2015). Use of a new integrational vector to investigate compartment-specific expression of the Bacillus. 705-711.

Sun, Y., Wilkinson, B. J., Standiford, T. J., Akinbi, H. T., and O’Riordan, M. X. D. (2012). Fatty acids regulate stress resistance and virulence factor production for Listeria monocytogenes. J Bacteriol 194, 5274-5284.

Temple, M. E. and Nahata, M. C. (2000). Treatment of listeriosis. Ann Pharmacother 34, 656-661.

Thomas, M. K., Vriezen, R., Farber, J. M., Currie, A., Schlech, W., and Fazil, A. (2015). Economic cost of a Listeria monocytogenes outbreak in Canada, 2008. Foodborne Pathog Dis 12, 966-971.

Tompkin, R. B. (2002). Control of Listeria monocytogenes in the food-processing environment. J Food Prot 65, 709-725. 
Twarog, R. and Wolfe, R. S. (1962). Enzymatic phosphorylation of butyrate. J Biol Chem $237,2474-2477$.

Vital, M., Howe, A. C., and Tiedje, J. M. (2014). Revealing the bacterial butyrate synthesis pathways by analyzing (meta)genomic data. Mbio 5, e00889.

Ward, D. E., Ross, R. P., van der Weijden, C. C., Snoep, J. L., and Clairborne A. (1999). Catabolism of branched-chain alpha-keto acids in Enterococcus faecalis: the bkd gene cluster, enzymes, and metabolic route. J Bacteriol 181, 5433-5442.

Wolfe, A. J. (2005). The acetate switch. Microbiol Mol Biol Rev 69, 12-50.

Zhao, Y., Tomas, C. A., Rudolph, F. B., Papoutsakis, E. T., and Bennett, G. N. (2005). Intracellular butyryl phosphate and acetyl phosphate concentrations in Clostridium acetobutylicum and their implications for solvent formation. Appl Environ Microbiol 71, 530-537.

Zhu, K., Ding, X., Julotok, M., and Wilkinson, B. J. (2005a). Exogenous isoleucine and fatty acid shortening ensure the high content of anteiso-C15:0 fatty acid required for low-temperature growth of Listeria monocytogenes. Appl Environ Microbiol $71,8002-8007$.

Zhu, K., Bayles, D. O., Xiong, A., Jayaswal, R. K., and Wilkinson, B. J. (2005b). Precursor and temperature modulation of fatty acid composition and growth of Listeria monocytogenes cold-sensitive mutants with transposon-interrupted branched-chain alpha-keto acid dehydrogenase. Microbiology 151, 615-23. 


\section{CHAPTER II}

\section{GROWTH OF A LISTERIA MONOCYTOGENES BKD-DEFICIENT MUTANT IN SERUM TO ANALYZE BRANCHED-CHAIN FATTY ACID PREFERENCE IN MEMBRANE INCORPORATION}

\section{Introduction}

Listeria monocytogenes, a foodborne bacterial pathogen, is capable of growth at low temperature due to homeoviscous adaptation. This modulation of membrane fluidity in response to environmental conditions (temperature, $\mathrm{pH}$, salt content, etc.) is performed by the incorporation of certain fatty acids (Annous et al., 1997; Giotis et al., 2007; Chihib et al., 2003). Addition of specific branched-chain fatty acids (BCFAs) is $L$. monocytogenes' primary method of achieving greater membrane fluidity, which is unlike other microorganisms that prefer the incorporation of unsaturated fatty acids (Fulco, 1983). Unsaturated fatty acids are typically undetectable in L. monocytogenes while BCFAs make up greater than $90 \%$ of the membrane when grown in conventional laboratory medium (Zhu et al., 2005).

The fatty acid profile of L. monocytogenes grown in vivo has not yet been sufficiently studied. In vivo conditions can be replicated by growth of L. monocytogenes in fetal bovine serum (FBS). FBS contains a high amount of straight-chain unsaturated fatty acids (SCUFAs) such as oleic acid (C18:1 $\Delta 9)$ and arachidonic acid (C20:4), which are present at approximately $30 \%$ and $10 \%$ of fatty acids, respectively (Stoll and Spector, 
1984). Palmitic acid (C16:0), a straight-chain saturated fatty acid, also makes up a large proportion of fatty acids in FBS at $20 \%$. Human serum is relatively similar in that it consists of high levels of palmitic acid (122 $\mu \mathrm{M})$, oleic acid (122 $\mu \mathrm{M})$, linoleic acid (84 $\mu \mathrm{M}, \mathrm{C} 18: 2 \Delta 9,12)$, and stearic acid (49 $\mu \mathrm{M}, \mathrm{C} 18: 0)$ (Psychogios et al., 2011).

Previous studies have made it clear that L. monocytogenes does not prefer to induce changes in total unsaturated fatty acid content of the membrane in response to environmental stress (Li et al., 2002; Nichols et al., 2002). Previously, it was of interest to examine the potential for changes in unsaturated fatty acid content in two BCFAdeficient mutants $c l d-1$ and $c l d-2$. Both contain a Tn917 transposon within the branchedchain $\alpha$-keto acid dehydrogenase (Bkd) gene cluster, thus interrupting expression of functional Bkd and incorporation of BCFAs into the membrane. Annous et al. (1997) found no evidence for production of unsaturated fatty acids or activity of a desaturating system when $c l d-1$ and cld-2 cultures were cold shocked. These studies were carried out in complex and defined medium.

MOR401 is a mutant with the $c l d-2$ transposon inserted into a clean wild type background; MOR401 shows reduced amounts of BCFAs and consequently, has a more rigid membrane (Sun et al., 2012; Sen et al., 2015). It is likely that MOR401 will also not favor unsaturated fatty acid incorporation into the membrane in standard medium. To what extent will this mutant lacking in membrane fluidity not utilize available, potential membrane-fluidizing SCUFAs? Growth in serum will assess MOR401's urgency for increased membrane fluidity and inclination towards BCFA incorporation in the membrane. Additional stress by culturing at $10^{\circ} \mathrm{C}$ should escalate the mutant's demand 
for increased membrane fluidity. An absence or low levels of increased growth or incorporation of SCUFAs will confirm L. monocytogenes' high preference for BCFAs. In addition, culturing of the mutant along with 2-methylbutyrate (2-MB) supplementation is also a test of preference; it is expected that the presence of anteiso C15:0 and anteiso C17:0 precursor 2-MB will override most of the uptake of SCUFAs into the membrane.

\section{Materials and Methods}

\section{Growth Studies}

In order to study the effects of serum on the growth and fatty acid composition of L. monocytogenes, wild type strain 10403S and MOR401 were grown in Brain Heart Infusion broth with $50 \%$ heat-inactivated $\mathrm{FBS}$ at $10^{\circ} \mathrm{C}$. Heat inactivation of FBS, in order to destroy complement proteins, was done by incubation in a water bath at $56^{\circ} \mathrm{C}$ for 30 minutes along with mixing every 5 minutes to ensure even heat distribution. One flask of MOR401 culture in 50\% FBS was supplemented with $1 \mathrm{mM} 2-\mathrm{MB}$.

\section{Membrane Fatty Acid Analysis}

Cultures were grown in BHI with or without supplementation and harvested at approximately an $\mathrm{OD}_{600}$ of 0.6 (mid-log phase). The culture volume of $5 \mathrm{~mL}$ was centrifuged at $3000 \times \mathrm{g}$ for 15 minutes at $4^{\circ} \mathrm{C}$ and pellets were washed three times with cold distilled $\mathrm{H}_{2} \mathrm{O}$. Fatty acid profiles were determined by Microbial ID, Inc. (Newark, DE) where the fatty acids within the cells (wet weight 30 to $40 \mathrm{mg}$ ) were saponified, methylated, and extracted. The methyl esters were separated with an Agilent 5890 dual 
tower gas chromatograph and determined using the MIDI microbial identification system (Sherlock 4.5 microbial identification system).

\section{Results}

To test the wild type strain and MOR401's growth in the presence of high levels of SCUFAs and SCFAs, they were cultured at $10^{\circ} \mathrm{C}$ in BHI and $50 \%$ FBS. The large effect of MOR401's growth in FBS and 2-MB tell us that SCUFAs are beneficial even to organisms without SCUFA production capability (Figure 1). MOR401 clearly benefitted from SCUFA incorporation; MOR401 grown in BHI failed to reach beyond an $\mathrm{OD}_{600}$ of 0.2 whereas MOR401 cultured in serum neared 0.8. Additionally, MOR401 grown in both serum and 2-MB nearly reached an $\mathrm{OD}_{600}$ of 1.4. Even though L. monocytogenes is not capable of producing SCUFAs, it is still able to benefit from them when available exogenously. And interestingly, the lag phase of MOR401 cultured in serum and 2-MB was shorter than serum-grown MOR401 without 2-MB. L. monocytogenes' preference distinctly lies with BCFA precursor 2-MB over the SCFAs and SCUFAs found in serum. In order to determine the membrane fatty acid content of MOR401 and wild type when grown in serum, fatty acid analysis was performed (Table 1). The results show that SCUFAs are incorporated in MOR401 to levels similar to that of S. aureus when grown in serum (Unpublished data). MOR401 takes up approximately 22\% of SCUFAs, but in the addition of 2-MB, that amount decreases to levels resembling wild type SCUFA incorporation. The most prominent SCUFA incorporated into the membrane was oleic 
acid $(\mathrm{C} 18: 1 \Delta 9)$, which accounts for the majority of the membrane SCUFAs in each sample, followed by vaccenic acid (C18:1 $\Delta 7)$ and palmitoleic acid $(\mathrm{C} 16: 1 \Delta 7)$.

Wild type incorporates nearly $13 \%$ SCUFAs and 17\% SCFAs at the expense of BCFAs, which only account for $69 \%$ of total membrane fatty acids when cultured in serum. The membrane of wild type grown in $100 \%$ BHI contains around $98 \%$ BCFAs and only 2\% SCFAs (Sen et al., 2015). Even though SCUFAs and SCFAs were included in the membrane of serum-grown wild type strain to such an extent, wild type grown with and without serum showed nearly identical growth curves. SCUFAs are clearly as advantageous to the organism as BCFAs when available in the environment.

\section{Discussion}

Because SCUFAs yield similar amounts of membrane fluidity as BCFAs (Zhang et al., 2008), it is not surprising that L. monocytogenes utilizes these host-derived FAs. But then why do SCFAs get incorporated to such an extent to where they consist of $20 \%$ of membrane fatty acids when L. monocytogenes clearly prefers membrane-fluidizing fatty acids? Given the results of our experiment, it could be said that L. monocytogenes uses any accessible fatty acids and fatty acid precursors in its environment, even if some of them do not increase membrane fluidity and therefore, do not provide advantageous biophysical properties. This phenomenon may be due to several factors which include energy preservation and the activation of signaling pathways to alter gene expression in certain environments. 
First, available fatty acid substrates are taken up and used in order to save the organism energy. De novo fatty acid biosynthesis is costly in terms of a cell's use of energy and carbon. In fact, $95 \%$ of the energy used in phospholipid biosynthesis is required for fatty acid production (Parsons et al., 2012). So, it is beneficial for the organism to take advantage of any available fatty acid substrate it encounters because that can lead to a large degree of overall energy savings.

Another reason for incorporation of non-advantageous fatty acids is that exogenous fatty acids added into the membrane could be involved in signaling mechanisms which lead to altered gene expression in certain environments. For example, when enterohemorrhagic E. coli (EHEC) is grown in the presence of common intestinal short chain fatty acids acetate, propionate, and butyrate, virulence factor expression is activated (Tobe et al., 2011). Also, Clostridium acetobutylicum alters expression of many genes in response to fatty acid precursors such as those which involve flagella formation and stress (Zhao et al., 2005). Gut fatty acids could serve as a trigger for the expression of genes which are advantageous during infection of a host. They could signal to the organism as to what sort of environment it currently resides in and whether virulence factors should be upregulated for proliferation and infection (Sun et al., 2012). 


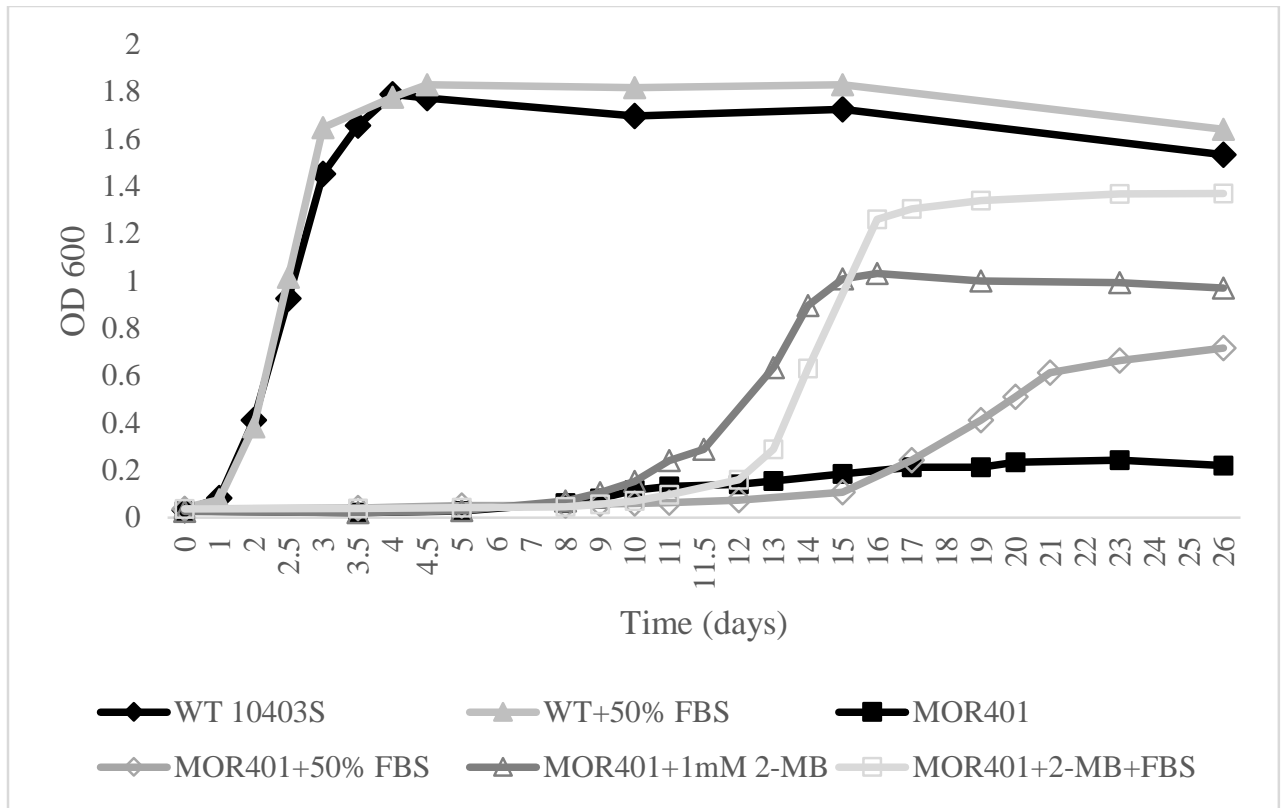

Figure 1. Growth of wild type 10403S and MOR401 in 50\% fetal bovine serum supplemented with 2-methylbutyrate at $10^{\circ} \mathrm{C}$. 


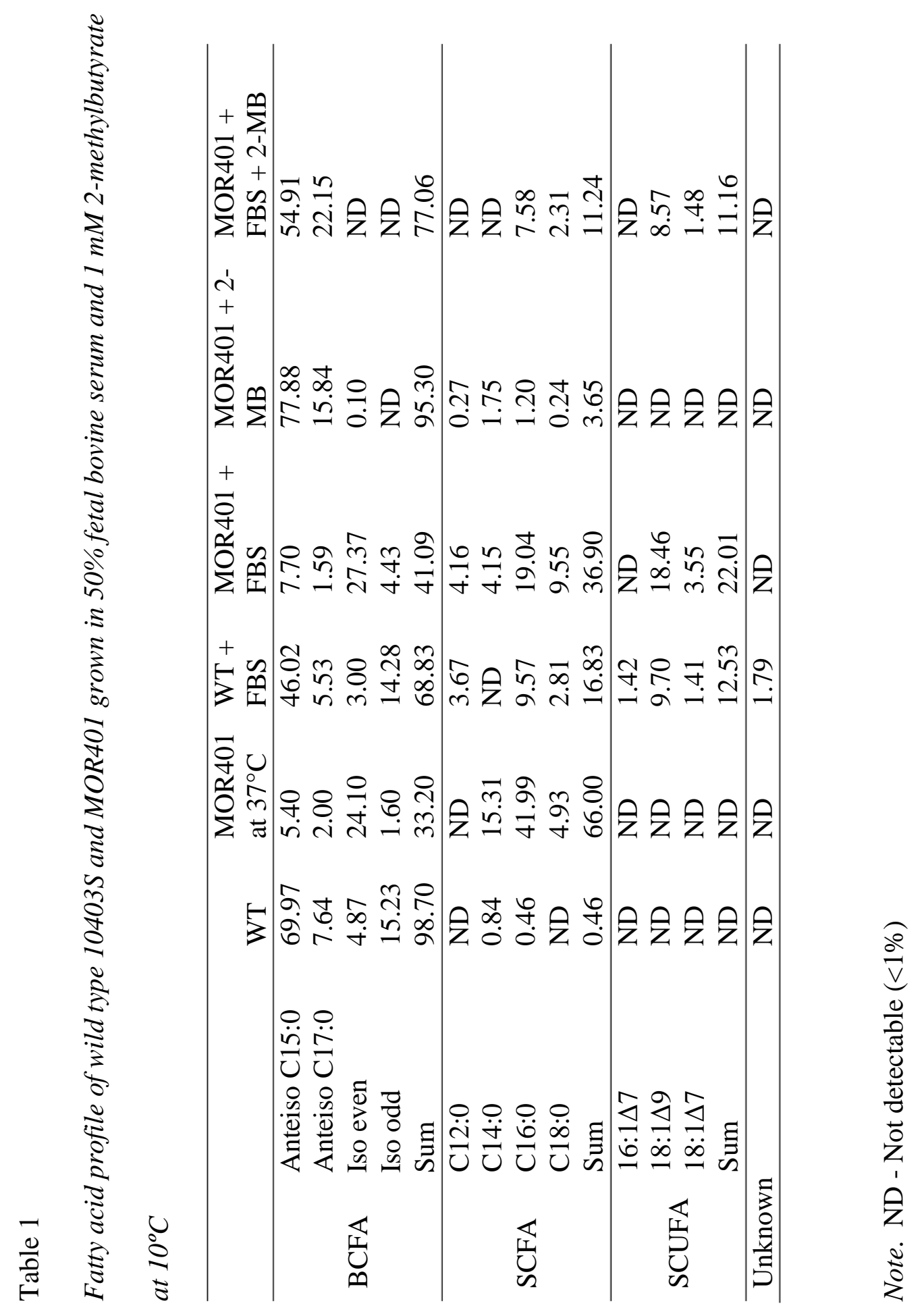




\section{REFERENCES}

Annous, B. A., Becker, L. A., Bayles, D. O., Labeda, D. P., and Wilkinson, B. J. (1997). Critical role of anteiso-C15:0 fatty acid in the growth of Listeria monocytogenes at low temperatures. Appl Environ Microbiol 63, 3887-3894.

Chihib N., Ribeiro da Silva, M., Delattre, G., Laroche, M., and Federighi, M. (2003). Different cellular fatty acid pattern behaviors of two strains of Listeria monocytogenes Scott A and CNL 895807 under different temperature and salinity conditions. FEMS Microbiol Lett 218, 155-160.

Fulco, A. J. (1983). Fatty acid metabolism in bacteria. Prog Lipid Res 22, 133-160.

Giotis, E. S., McDowell, D. A., Blair, I. S., and Wilkinson, B. J. (2007). Role of branched-chain fatty acids in $\mathrm{pH}$ stress tolerance in Listeria monocytogenes. Appl Environ Microbiol 73, 997-1001.

Li, J, Chikindas, M. L., Ludescher, R. D., and Montville, T. J. (2002). Temperature- and surfactant-induced membrane modifications that alter Listeria monocytogenes nisin sensitivity by different mechanisms. Appl Environ Microbiol 68, 5904-10.

Nichols, D. S., Presser, K. A., Olley, J., Ross, T., and McMeekin, T. A. (2002). Variation of branched-chain fatty acids marks the normal physiological range for growth in Listeria monocytogenes. Appl Environ Microbiol 68, 2909-2813.

Psychogios, N., Hau, D. D., Peng, J., Guo, A. C., Rupasri, M., Bouatra, S., Sinelnikov, I., Krishnamurthy, R., Eisner, R., Gautam, B., Young, N., Xia, J., Knox, C., Dong, E., Huang, P., Hollander, Z., Pedersen, T. L., Smith, S. R., Bamforth, F., Greiner, R., McManus, B., Newman, J. W., Goodfriend, T., and Wishart, D. S. (2011). The human serum metabolome. 6, e16957.

Sen, S., Sirobhushanam, S., Hantak, M. P., Lawrence, P., Brenna, J. T., Gatto, C., and Wilkinson, B. J. (2015). Short branched-chain C6 carboxylic acids result in increased growth, novel 'unnatural' fatty acids and increased membrane fluidity in a Listeria monocytogenes branched-chain fatty acid-deficient mutant. BBA Mol Cell Biol Lipids 1851, 1406-1415. Elsevier B.V.

Stoll, L. L. and Spector A. A. (1984). Changes in serum influence the fatty acid composition of established cell lines. In vivo 20, 732-8. 
Sun, Y., Wilkinson, B. J., Standiford, T. J., Akinbi, H. T., and O’Riordan, M. X. D. (2012). Fatty acids regulate stress resistance and virulence factor production for Listeria monocytogenes. J Bacteriol 194, 5274-5284.

Tobe, T., Nakanishi, N., and Sugimoto, N. (2011). Activation of motility by sensing short-chain fatty acids via two steps in a flagellar gene regulatory cascade in enterohemorrhagic Escherichia coli. Infect Immun 79, 1016-1024.

Zhao, Y., Tomas, C. A., Rudolph, F. B., Papoutsakis, E. T., and Bennett, G. N. (2005). Intracellular butyryl phosphate and acetyl phosphate concentrations in Clostridium acetobutylicum and their implications for solvent formation. Appl Environ Microbiol 71, 530-537.

Zhu, K., Bayles, D. O., Xiong, A., Jayaswal, R. K., and Wilkinson, B. J. (2005). Precursor and temperature modulation of fatty acid composition and growth of Listeria monocytogenes cold-sensitive mutants with transposon-interrupted branched-chain alpha-keto acid dehydrogenase. Microbiology 151, 615-23. 
CHAPTER III

THE EFFECTS OF NOVEL FATTY ACIDS DERIVED FROM SHORT BRANCHEDCHAIN C6 CARBOXYLIC ACIDS ON THE FUNCTIONAL MEMBRANE REQUIREMENTS OF A LISTERIA MONOCYTOGENES

\section{BCFA-DEFICIENT MUTANT}

\section{Introduction}

Listeria monocytogenes is a foodborne pathogen implicated in listeriosis, a potentially fatal infection in pregnant women and individuals with compromised immune systems. One of this microorganism's distinguishing and threatening features is its ability to grow at cold temperatures, which is due to the regulation of specific fatty acid incorporation into membrane phospholipids (Shabala et al., 2008; Giotis et al., 2007; Sun et al., 2012). Branched-chain fatty acids (BCFAs) typically make up greater than $90 \%$ of membrane fatty acids in most conditions while straight-chain fatty acids make up the remainder (Annous et al., 1997). BCFA anteiso C15:0 yields the greatest membrane fluidity, so this BCFA is incorporated to a higher degree when the organism is grown at low temperature (Edgcomb et al., 2000).

MOR401, a transposon mutant with an insertion in the branched-chain $\alpha$-keto acid dehydrogenase operon, is deficient in BCFAs (Sun et al., 2010). However, supplementation of short branched-chain carboxylic acids such as 2-methylbutyrate (2$\mathrm{MB})$ restore the mutant's growth, fatty acid composition, and membrane fluidity. It was 
also determined that feeding MOR401 2-MB restored the mutant's intracellular survival and growth, colocalization with actin, and production of listeriolysin. Later studies confirmed that supplementation decreased sensitivity to various antimicrobials and increased phagosomal survival (Sun et al., 2012). Growth with 2-MB was found to satisfy MOR401's membrane functional requirements by the recovery of anteiso odd BCFA levels.

Recently, Sen et al. (2015) discovered that supplementation of growth media with several branched-chain C6 isomers, which are also BCFA precursors, such as 2ethylbutyrate (2-EB) and 2-methylpentanoate (2-MP) led to production of various unnatural fatty acids in MOR401. When the mutant was supplemented with 2-MP, novel fatty acids were found to make up nearly $75 \%$ of membrane fatty acids. In addition, the precursors which produced these novel fatty acids restored BCFA membrane levels, growth at low temperature, and membrane fluidity.

It is unknown if addition of 2-EB and 2-MP, along with subsequent incorporation and creation of novel fatty acids, will also satisfy the previously studied functional requirements of the membrane, as 2-MB was capable of fulfilling. In order to determine whether these short branched-chain C6 carboxylic acids are also able to recover MOR401's survival in the presence of antimicrobials, an assay was carried out as described by Sun et al. (2010). 


\section{Materials and Methods}

Cultures were grown to an $\mathrm{OD}_{600}$ of 0.6 where the cells were diluted $10^{-5}$ in 10 $\mathrm{mM}$ potassium phosphate buffer $(\mathrm{pH}$ 5.8) and aliquoted into a microtiter plate. The suspended cells were mixed with serially diluted solutions of polymyxin B, protamine sulfate, and mutanolysin and incubated for 1 hour at $37^{\circ} \mathrm{C}$. Colonies after 0 hours and 1 hour were enumerated by plating on BHI agar. Percent survival was calculated with the following equation: \% survival $=\left(\mathrm{CFU}_{\mathrm{T}=1 \mathrm{~h}} / \mathrm{CFU} \mathrm{T=0}\right) \times 100$.

\section{Results}

To test how effectively the unnatural fatty acids in the membrane of 2-EB and 2MP-supplemented MOR401 restore the mutant's ability to survive under stress, MOR401 was grown with 2-EB and 2-MP followed by an hour-long incubation in the presence of polymyxin B (negative control), protamine, and mutanolysin. As shown in Figure 1, the assays testing incubation with polymyxin B and mutanolysin were not able to be replicated from Sun et al. (2010) despite numerous attempts to correct plating technique, buffer preparation, and antimicrobial dilution calculations. Yet, the assay analyzing MOR401 growth with protamine did yield the predicted results. When fed 2-EB and 2MP, MOR401 displayed restored survival when grown with protamine. Wild type and MOR401 grown with 2-MB, 2-EB, and 2-MP were able to maintain viable cells when subjected to protamine. 


\section{Discussion}

When BCFA-deficient MOR401 was fed 2-MB and cultured with various antimicrobials in Sun et al. (2012), membrane fluidity was restored and survivability of the mutant was drastically increased. More recently, it was discovered that unnatural BCFA precursors 2-EB and 2-MP also give rise to a more fluid membrane (Sen et al., 2015). This study sought to investigate the degree to which incorporation of 2-EB and 2MP satisfy the functional requirements of the membrane.

However, problems were encountered. The assays testing MOR401 survival against polymyxin B and mutanolysin lead to unnaturally low colony counts of all strains tested, including wild type which is resistant to polymyxin B and mutanolysin under normal circumstances. Polymyxin B was supposed to have served as the negative control; it is a cationic antimicrobial peptide (CAMP) which only exhibits bactericidal activity against most Gram-negative bacteria. The peptide penetrates the organism's outer membrane and increases its permeability by weakening interactions between lipopolysaccharides (Vaara et al., 1992). Mutanolysin from Streptomyces globisporus is similar to lysozyme, an enzyme present in macrophages, because it cleaves peptidoglycan through $\mathrm{N}$-acetylmuramidase activity (Fliss et al., 1991). To bypass this, $L$. monocytogenes is supposed to be able to modify the targeted peptidoglycan by deacetylation of N-acetylglucosamine by PgdA (Boneca et al., 2007) and by Oacetylation due to OatA (Aubry et al., 2011).

Protamine is a CAMP whose antimicrobial activity involves electrostatic interactions between the peptide and bacterial envelope followed by disruption of the 
membrane (Potter et al., 2004). This study has shown that incorporation of novel BCFAs into L. monocytogenes' membrane largely contributes to protamine resistance.

Errors in calculating concentrations of mutanolysin or preparing the buffer could have contributed to the issues regarding the polymyxin B and mutanolysin assays. The acidic $\mathrm{pH}$ of the buffer was of concern at first, but this was found to be tested previously; acidic buffers with pH 5.0 and 7.0 were examined with wild type and MOR401 growth and little difference was observed (Sun et al., 2012). In fact, the acidity of the buffer causes cell wall peptidoglycan to become neutral or slightly positively charged, which causes CAMPs to be less attracted to peptidoglycan (Walkenhorst et al., 2013). Clearly, more work needs to be done in order to identify errors in experiment execution and eliminate issues involving buffer and antimicrobial preparation. 

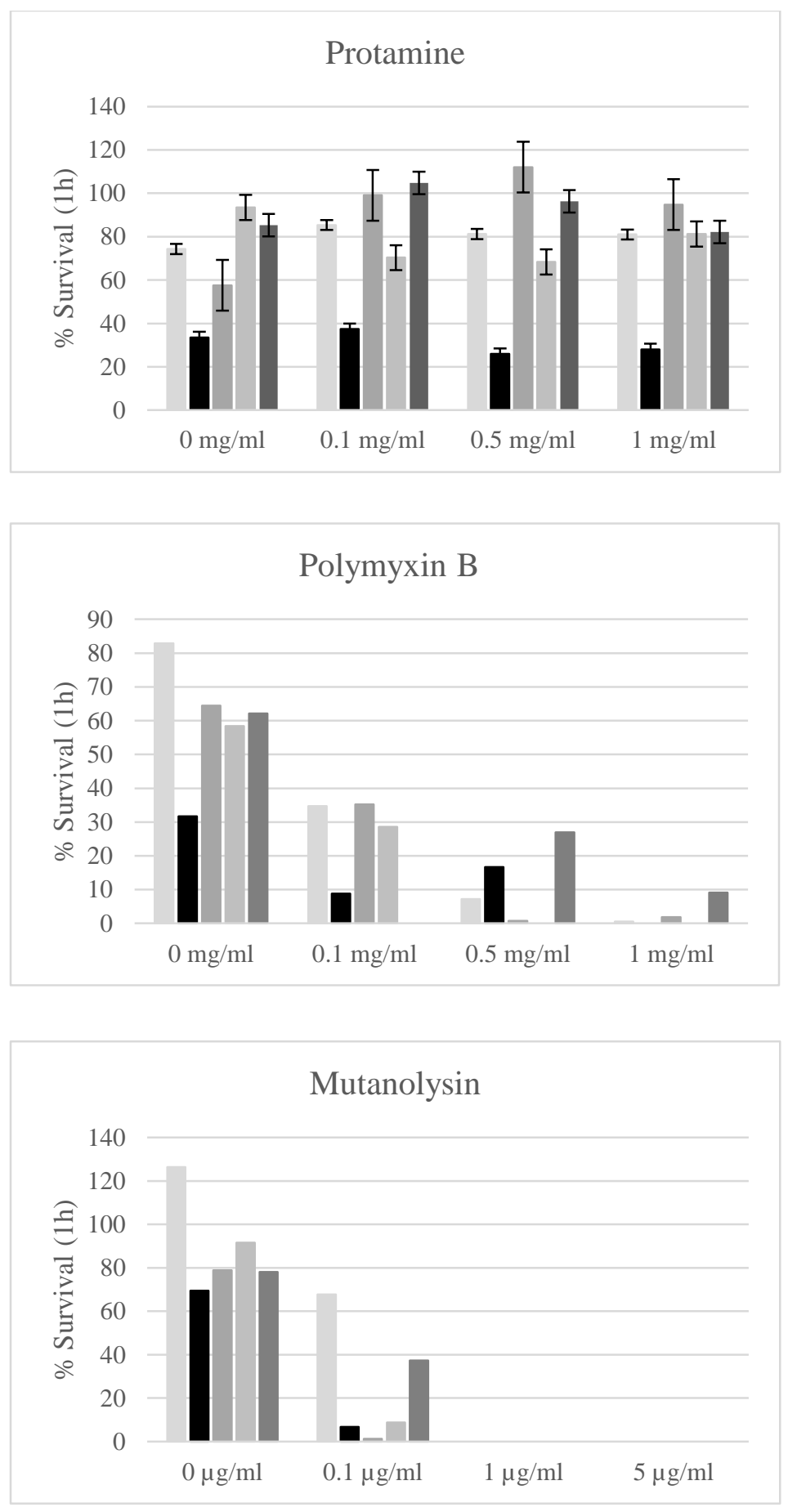

WT $\square$ MOR401 $\square$ MOR401+2MB $\square$ MOR401+2EB $\square \mathrm{MOR} 401+2 \mathrm{MP}$

Figure 1. The survival of MOR401 grown in the presence of branched-chain fatty acid precursors against protamine sulfate, polymyxin $\mathrm{B}$, and mutanolysin. 


\section{REFERENCES}

Annous, B. A., Becker, L. A., Bayles, D. O., Labeda, D. P., and Wilkinson, B. J. (1997). Critical role of anteiso-C15:0 fatty acid in the growth of Listeria monocytogenes at low temperatures. Appl Environ Microbiol 63, 3887-3894.

Aubry, C., Goulard, C., Nahori, M., Cayet, N., Decalf, J., Sachse, M., Boneca, I. G., Cossart, P., and Dussurget, O. (2011). OatA, a peptidoglycan O-acetyltransferase involved in Listeria monocytogenes immune escape, is critical for virulence. $\mathrm{J}$ Infect Dis 204, 731-740.

Boneca, I. G., Dussurget, O., Cabanes, D., Nahori, M. A., Sousa, S., Lecuit, M., Psylinakis, E., Bouriotis, V., Hugot, J. P., Giovannini, M., Coyle, A., Bertin, J., Namane, A., Rousselle, J. C., Cayet, N., Prévost, M. C., Balloy, V., Chignard, M., Philpott, D. J., Cossart, P., and Girardin, S. E. (2007). A critical role for peptidoglycan N-deacetylation in Listeria evasion from the host innate immune system. Proc Natl Acad Sci USA 104, 997-1002.

Edgcomb, M. R., Sirimanne, S., Wilkinson, B. J., Drouin, P., and Morse, R. D. (2000). Electron paramagnetic resonance studies of the membrane fluidity of the foodborne pathogenic psychrotroph Listeria monocytogenes. Biochim Biophys Acta $1463,31-42$.

Fliss, I., Emond E., Simard, R. E., and Pandian, S. (1991). A rapid and efficient method of lysis of Listeria and other Gram-positive bacteria using mutanolysin. Biotechniques 453, 456-457.

Giotis, E. S., McDowell, D. A., Blair, I. S., and Wilkinson, B. J. (2007). Role of branched-chain fatty acids in $\mathrm{pH}$ stress tolerance in Listeria monocytogenes. Appl Environ Microbiol 73, 997-1001.

Potter, R, Truelstrup Hansen L., and Gill, T. A. (2004). Inhibition of foodborne bacteria by native and modified protamine: importance of electrostatic interactions. Int $\mathbf{J}$ Food Microbiol 103, 23-34.

Sen, S., Sirobhushanam, S., Hantak, M. P., Lawrence, P., Brenna, J. T., Gatto, C., and Wilkinson, B. J. (2015). Short branched-chain C6 carboxylic acids result in increased growth, novel 'unnatural' fatty acids and increased membrane fluidity 
in a Listeria monocytogenes branched-chain fatty acid-deficient mutant. BBA Mol Cell Biol Lipids 1851, 1406-1415. Elsevier B.V.

Shabala, L., Lee, S. H., Cannesson, P., and Ross, T. (2008). Acid and NaCl limits to growth of Listeria monocytogenes and influence of sequence of inimical acid and $\mathrm{NaCl}$ levels on inactivation kinetics. J Food Prot 71, 1169-1177.

Sun, Y. and O'Riordan, M. (2010). Branched-chain fatty acids promote Listeria monocytogenes intracellular infection and virulence. Infection and Immunity 78, 4667-73.

Sun, Y., Wilkinson, B. J., Standiford, T. J., Akinbi, H. T., and O'Riordan, M. X. D. (2012). Fatty acids regulate stress resistance and virulence factor production for Listeria monocytogenes. J Bacteriol 194, 5274-5284.

Vaara, M. (1992). Agents that increase the permeability of the outer membrane. Microbiol Revs 56, 395-41.

Walkenhorst, W. F., Klein, J. W., Vo, P., and Wimley, W. C. (2013). pH dependence of microbe sterilization by cationic antimicrobial peptides. Antimicrob Agents Chemother 57, 3312-3320. 